\author{
RESEARCH ARTICLE \\ 10.1029/2019JC015544 \\ Key Points: \\ - The maximum quantification limits \\ for ${ }^{223} \mathrm{Ra}$ and ${ }^{224} \mathrm{Ra}$ are 200 and \\ $100 \mathrm{cpm}$ in the total channel, \\ respectively \\ - Limits for the quantification of ${ }^{223} \mathrm{Ra}$ \\ and ${ }^{224} \mathrm{Ra}$ are provided when \\ measurements are influenced by \\ cross-talk and ${ }^{222} \mathrm{Rn}$ buildup effect \\ - The understanding of RaDeCC \\ counting systematics derived from \\ simulations allowed improving the \\ quantification of ${ }^{226} \mathrm{Ra}$ via ${ }^{222} \mathrm{Rn}$ \\ buildup
}

Correspondence to:

M. Diego-Feliu and V. Rodellas

marc.diego@uab.cat;

valenti.rodellas@uab.cat

Citation:

Diego-Feliu, M., Rodellas, V., Alorda-Kleinglass, A., Tamborski, J., van Beek, P., Heins, L., et al. (2020). Guidelines and Limits for the Quantification of Ra Isotopes and Related Radionuclides With the Radium Delayed Coincidence Counter (RaDeCC). Journal of Geophysical Research: Oceans, 125, e2019JC015544. https://doi.org/10.1029/2019JC015544

Received 12 AUG 2019

Accepted 25 MAR 2020

Accepted article online 27 MAR 2020

(C)2020. American Geophysical Union. All Rights Reserved.

\section{Guidelines and Limits for the Quantification of Ra Isotopes and Related Radionuclides With the Radium Delayed Coincidence Counter (RaDeCC)}

\author{
M. Diego-Feliu' ${ }^{1}$, V. Rodellas ${ }^{1}$ (D), A. Alorda-Kleinglass' ${ }^{1}$ (D) J. Tamborski ${ }^{2,3}$ (D) P. van Beek ${ }^{4}$, \\ L. Heins ${ }^{5}$, J. M. Bruach ${ }^{1,6}$ (D), R. Arnold ${ }^{7}$, and J. Garcia-Orellana ${ }^{1,6}$ (iD \\ ${ }^{1}$ ICTA, Institut de Ciència i Tecnologia Ambientals, Universitat Autònoma de Barcelona, Bellaterra, Spain, ${ }^{2}$ Department \\ of Marine Chemistry and Geochemistry, Woods Hole Oceanographic Institution, Woods Hole, MA, USA, ${ }^{3}$ Centre for \\ Water Resources Studies, Dalhousie University, Halifax, NS, Canada, ${ }^{4}$ LEGOS, Laboratoire d'Etudes en Géophysique et \\ Océanographie Spatiales, Université de Toulouse, CNES, CNRS, IRD, UPS, Observatoire Midi Pyrénées, Toulouse, France, \\ ${ }^{5}$ AWI, Alfred Wegener Institute, Helmholtz Centre for Polar and Marine Research, Bremerhaven, Germany, \\ ${ }^{6}$ Departament de Física, Universitat Autònoma de Barcelona, Bellaterra, Spain, ${ }^{7}$ Scientific Computer Instruments, West \\ Columbia, SC, USA
}

Abstract The Radium Delayed Coincidence Counter (RaDeCC) is one of the most extensively used equipment for measuring ${ }^{223} \mathrm{Ra}$ and ${ }^{224} \mathrm{Ra}$ activities in water and sediment samples. Samples are placed in a closed He-circulation system that carries the $\mathrm{Rn}$ produced by the decay of $\mathrm{Ra}$ to a scintillation cell. Each alpha decay recorded in the cell is routed to an electronic delayed coincidence system which enables the discrimination of ${ }^{223} \mathrm{Ra}$ and ${ }^{224} \mathrm{Ra}$. In this study, the measurement and quantification methods using the RaDeCC system are assessed through analyses of registered data in different RaDeCC systems worldwide and a set of simulations. Results of this work indicate that the equations used to correct for ${ }^{223} \mathrm{Ra}$ and ${ }^{224} \mathrm{Ra}$ cross-talk interferences are only valid for a given range of activities and ratios between isotopes. Above certain limits that are specified in this study, these corrections may significantly overestimate the quantification of ${ }^{223} \mathrm{Ra}$ and ${ }^{224} \mathrm{Ra}$ activities (up to $\sim 40 \%$ and $30 \%$, respectively), as well as the quantification of their parents ${ }^{227} \mathrm{Ac}$ and ${ }^{228} \mathrm{Th}$. High activities of ${ }^{226} \mathrm{Ra}$ may also produce an overestimation of ${ }^{224} \mathrm{Ra}$ activities due to the buildup of ${ }^{222} \mathrm{Rn}$, especially when long measurements with low activities of ${ }^{224} \mathrm{Ra}$ are performed. An improved method to quantify ${ }^{226} \mathrm{Ra}$ activities from the buildup of ${ }^{222} \mathrm{Rn}$ with the RaDeCC system is also developed in this study. Wethus provide a new set of guidelines for the appropriate quantification of ${ }^{223} \mathrm{Ra},{ }^{224} \mathrm{Ra},{ }^{227} \mathrm{Ac},{ }^{228} \mathrm{Th}$, and ${ }^{226} \mathrm{Ra}$ with the RaDeCC system.

Plain Language Summary In the last decades, there has been a growing interest in using radioactive isotopes to evaluate environmental processes. Their concentrations in environmental settings can reveal information about provenance, path, time, and duration. In this scenario, the research in the techniques to measure isotopes from samples has played a key role. In 1996, the launching of the Radium Delayed Coincidence Counter (RaDeCC) facilitated the fast and precise measurement of Ra isotopes, which provide information on land-ocean interaction processes (e.g., groundwater discharge to the sea and coastal residence times). Nowadays, this detector has become a fundamental tool for oceanographers, geochemist, and hydrologist among other scientific communities. Nevertheless, when the RaDeCC system was released, its quantification limits were not provided, and the recommendations on its use were mostly qualitative. More than 20 years later, we address these questions in a study that contains a comprehensive analysis of the RaDeCC counting mechanism and the determination of the limits of quantification. This study should serve as guidance for the measurement and quantification of Radium isotopes for the scientific community using the RaDeCC system.

\section{Introduction}

Short-lived Ra isotopes $\left({ }^{223} \mathrm{Ra}, T_{1 / 2}=11.4\right.$ days; ${ }^{224} \mathrm{Ra}, T_{1 / 2}=3.66$ days $)$ have been widely applied to estimate fluxes of submarine groundwater discharge (SGD) (e.g., Burnett et al., 2006; Charette et al., 2013; Garcia-Orellana et al., 2014), pore-water exchange (e.g., Alorda-Kleinglass et al., 2019; Hong et al., 2018; 
Rodellas et al., 2017), and to determine water residence time and coastal mixing rates (e.g., Knee et al., 2011; Moore, 2000; Moore \& Oliveira, 2008).

The Radium Delayed Coincidence Counter (RaDeCC) has become the most extensively used equipment to measure short-lived $\mathrm{Ra}$ isotopes due to the simplicity and sensitivity of the detection technique, the relatively low operational cost, and its portability. The counter is used to measure water samples from different settings such as seawater, pore-water, groundwater, rivers, or water from brines (e.g., Moise et al., 2000; Moore et al., 2011; Moore \& Krest, 2004). Recently, there has been a renewed interest in using the RaDeCC system to analyze sediment samples (Cai et al., 2012, 2014). Moreover, this system has also been employed to measure other isotopes such as ${ }^{227} \mathrm{Ac}$ and ${ }^{228} \mathrm{Th}$, in secular equilibrium with their daughters $\left({ }^{223} \mathrm{Ra}\right.$ and ${ }^{224} \mathrm{Ra}$, respectively) and ${ }^{228} \mathrm{Ra}$ and ${ }^{226} \mathrm{Ra}$ through the ingrowth of ${ }^{228} \mathrm{Th}$ and ${ }^{222} \mathrm{Rn}$, respectively (Geibert et al., 2013; Le Roy et al., 2019; Moore, 2008; Waska et al., 2008), enlarging the number of its applications. Although the system was originally designed to measure low activity ${ }^{223} \mathrm{Ra}$ and ${ }^{224} \mathrm{Ra}$ samples (Giffin et al., 1963; Moore \& Arnold, 1996), samples commonly measured with the RaDeCC system span a wide range of ${ }^{223} \mathrm{Ra}$ and ${ }^{224} \mathrm{Ra}$ concentrations. Ra activities may be especially high in pore water and coastal aquifer samples given the influence of several parameters on Ra activities such as salinity, geological context, or water-sediment ratio (Cerdà-Domènech et al., 2017; Gonneea et al., 2013). However, the influence of different initial ${ }^{223} \mathrm{Ra},{ }^{224} \mathrm{Ra}$, and ${ }^{226} \mathrm{Ra}$ activities (and their activity ratios) in the quantification systematics of the RaDeCC system have never been studied in detail. In this work, we examine the behavior of the counting system under different activities and activity ratios of ${ }^{223} \mathrm{Ra},{ }^{224} \mathrm{Ra}$, and ${ }^{226} \mathrm{Ra}$ through a set of simulations that reproduce the RaDeCC counting mechanism. The input data of the simulations is based on the statistical analysis of data registered by different laboratories worldwide using the RaDeCC system. Simulation results were used to define the maximum quantification limits of the RaDeCC system, which were validated against real measurements. According to the results, we provide new guidelines in the determination of the activities of ${ }^{227} \mathrm{Ac},{ }^{228} \mathrm{Th}$, and Ra isotopes with the RaDeCC system.

\section{Principles of Measurement and Quantification With the RaDeCC System}

\subsection{Description of the Detection System}

Measurements of short-lived Ra isotopes in water and sediment samples with the RaDeCC system generally require preconcentration with $\mathrm{Mn}$ hydroxides. Water samples are usually filtered through $\mathrm{MnO}_{2}$-impregnated acrylic fibers (hereinafter Mn-fibers) that quantitatively extract Ra isotopes from solution in case of slow filtration $\left(<1 \mathrm{~L} \mathrm{~min}^{-1}\right)$ (Moore, 1976). Alternatively, cartridges impregnated with $\mathrm{MnO}_{2}$ (hereinafter Mn-cartridges) have also been used for large volume samples (e.g., open sea water samples; Le Roy et al., 2019; Sanial et al., 2018). Sediment samples can be directly measured with the RaDeCC system (Sun \& Torgersen, 1998a; Tamborski et al., 2019) or mixed with Milli-Q water to form a slurry, which is filtered after coprecipitation of $\mathrm{Ra}$ isotopes in the interstitial water by $\mathrm{MnO}_{2}$ suspension (Cai et al., 2012). After adjusting the moisture of Mn-fibers, Mn-cartridges, or sediments (Cai et al., 2012; Sun \& Torgersen, 1998b), samples are placed in a sample chamber connected to a closed He-circulation loop. The He gas carries the decay products of adsorbed ${ }^{223} \mathrm{Ra}$ and ${ }^{224} \mathrm{Ra}\left({ }^{219} \mathrm{Rn}\right.$ and ${ }^{220} \mathrm{Rn}$, respectively) from the sample chamber to a 1.1 L ZnS phosphor scintillation cell (Lucas cell). When an alpha particle resulting from the decay of $\mathrm{Rn}$ (or its daughters) strikes the $\mathrm{ZnS}$, light is emitted. Then, a photomultiplier tube (PMT) connected to the cell converts the light into an electronic pulse, which is amplified and directed to a delayed coincidence circuit (DCC). The DCC, originally pioneered by Giffin et al. (1963) for the assay of ${ }^{219} \mathrm{Rn}$ and ${ }^{220} \mathrm{Rn}$ from a $5 \mathrm{~mL}$ acid solution containing their parents $\left({ }^{231} \mathrm{~Pa}\right.$ and ${ }^{232} \mathrm{Th}$, respectively), was later adapted for short-lived $\mathrm{Ra}$ isotopes measurements (after preconcentration onto Mn-fibers) by Moore and Arnold (1996). The DCC discriminates between ${ }^{223} \mathrm{Ra}$ and ${ }^{224} \mathrm{Ra}$, based on the half-lives of the ${ }^{219} \mathrm{Rn}$ and ${ }^{220} \mathrm{Rn}$ daughter isotopes $\left({ }^{215} \mathrm{Po}\right.$ and ${ }^{216} \mathrm{Po}$, respectively) (Figure 1$)$.

After any alpha decay is detected in the scintillation cell, three electronic circuits are triggered: the 219, the 220, and the Total circuit (Figure 1). The electronics of the 219 and 220 circuit are designed to record a count only if it occurs within a specific time interval. After a delay of $0.01 \mathrm{~ms}\left(t_{D-219}\right)$ from the triggering event (to allow the elimination of the triggering pulse; Giffin et al., 1963), the 219 circuit is opened for $5.6 \mathrm{~ms}\left(t_{G-219}\right)$ $\left(\sim 3 \cdot \mathrm{T}_{1 / 2}\right.$ of $\left.{ }^{215} \mathrm{Po}\right)$ registering any subsequent event in the so-called 219 channel. Simultaneously, the 220 

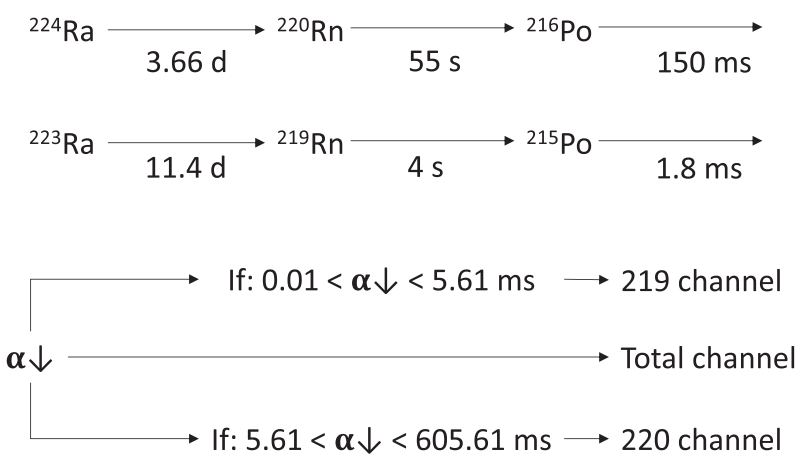

Figure 1. Decay systematics of ${ }^{224} \mathrm{Ra}$ and ${ }^{223} \mathrm{Ra}$ and schematic diagram of the delayed coincidence circuit. Based on Moore and Arnold (1996). circuit is opened for $600 \mathrm{~ms}\left(t_{G-220}\right)\left(\sim 4 \cdot \mathrm{T}_{1 / 2}\right.$ of $\left.{ }^{216} \mathrm{Po}\right)$ with a previous delay of $5.61 \mathrm{~ms}\left(t_{D-220}\right)$ in order to reduce the probability of a ${ }^{215}$ Po produced from ${ }^{219} \mathrm{Rn}$ decaying in this time interval. Any decay event occurring within this time interval is recorded in the 220 channel. The total channel records every decay event during the measurement period. Apart from the Rn-Po pairs, any other alpha decay products of ${ }^{223} \mathrm{Ra},{ }^{224} \mathrm{Ra}$, and ${ }^{226} \mathrm{Ra}$ (e.g., ${ }^{222} \mathrm{Rn},{ }^{218} \mathrm{Po},{ }^{214} \mathrm{Po},{ }^{212} \mathrm{Bi}$, and ${ }^{211} \mathrm{Bi}$ ) can also trigger or be counted in the three-circuit system.

Giffin et al. (1963) developed the chance coincidence equation to determine the number of random events occurring within the opening time of each gate $(Y C C)$. To do so, the number of triggering events (i.e., events that initiate the opening of the circuits) and the opening time of the gate $\left(t_{G}\right)$ should be known. While the opening time of the gate can be configured from the RaDeCC setup, the number of triggering events is calculated after performing a measurement by subtracting the coincident events (219 and 220 channel) from the total number of events (total channel) (equation 1).

$$
Y C C=\frac{(\text { cpmTot }- \text { cpm } 219-c p m 220)^{2} t_{G}(\min )}{1-\left(\text { cpmTot }- \text { cpm219-cpm220) } t_{G}(\min )\right.} .
$$

Additionally, Moore and Arnold (1996) developed a detailed quantification protocol not only to correct the count rate recorded in each channel for chance coincidence but also for 219-220 cross-talk interferences, i.e., the number of counts relative to Rn-Po events that are registered in the nonrespective channel. For high activity measurements (>10 cpm in the total channel), Moore and Arnold (1996) recommended the use of the count rate in the Total channel corrected for background in order to determine the ${ }^{224} \mathrm{Ra}$ activities. The associated uncertainties derived from the counting were developed in Garcia-Solsona et al. (2008).

The common procedure to quantify both ${ }^{223} \mathrm{Ra}$ and ${ }^{224} \mathrm{Ra}$ activities from water samples using the RaDeCC system usually involves multiple measurements (Moore, 2008). The first run is conducted shortly after sample collection (1-5 days) in order to determine ${ }^{223} \mathrm{Ra}$ and ${ }^{224} \mathrm{Ra}$ activities. In case of high activities of ${ }^{224} \mathrm{Ra}$ ( $>7$ cpm in the 220 channel; Scholten et al., 2010), a second measurement is performed a week later to quantify ${ }^{223} \mathrm{Ra}$, when the ${ }^{224} \mathrm{Ra}$ has decreased by $\sim 75 \%$, thereby reducing the ${ }^{220} \mathrm{Rn}^{-216} \mathrm{Po}$ chance coincidence events in the 219 channel. In order to determine the activities of ${ }^{227} \mathrm{Ac}$ and ${ }^{228} \mathrm{Th}$, another measurement is performed after 21 days for ${ }^{228} \mathrm{Th}$ and 3 months for ${ }^{227} \mathrm{Ac}$ when their daughters $\left({ }^{223} \mathrm{Ra}\right.$ and ${ }^{224} \mathrm{Ra}$, respectively) are in secular equilibrium, allowing the concurrent quantification of ${ }^{223} \mathrm{Ra}$ and ${ }^{224} \mathrm{Ra}$ excess activities (i.e., activity not supported by the parent; ${ }^{223} \mathrm{Ra}_{\mathrm{ex}}$ and ${ }^{224} \mathrm{Ra}_{\mathrm{ex}}$ ). An additional measurement can be performed after a certain period of time (usually more than 6 months; Moore, 2008) to determine the activity of ${ }^{228} \mathrm{Ra}$ by comparing the activity of ${ }^{228} \mathrm{Th}$ produced by the decay of ${ }^{228} \mathrm{Ra}$ with the initial activity of ${ }^{228} \mathrm{Th}$ (21-30 days after sample collection). Simultaneously, activities of ${ }^{226} \mathrm{Ra}$ can be quantified via the rate of ingrowth of ${ }^{222} \mathrm{Rn}$ during the measurement (Geibert et al., 2013). Alternatively, ${ }^{226} \mathrm{Ra}$ can be also determined following the method described by Waska et al. (2008), which consists of hermetically sealing the $\mathrm{Mn}$-fibers in a column for a few days and subsequently measuring the ingrown of ${ }^{222} \mathrm{Rn}$ with the RaDeCC system. In the case of bulk sediments, a single measurement 1 month after sample collection is sufficient to determine surface-bound ${ }^{223} \mathrm{Ra}$ and ${ }^{224} \mathrm{Ra}$ using the RaDeCC system (Sun \& Torgersen, 1998a; Tamborski et al., 2019). When measuring sediments for ${ }^{224} \mathrm{Ra}:{ }^{228} \mathrm{Th}$ disequilibrium determination via $\mathrm{RaDeCC}$, three different measurements are performed. A first run is performed within $\sim 12$ hours of sediment collection to determine the initial ${ }^{224} \mathrm{Ra}$, while second (8-10 days after collection) and third ( $\sim 25$ days after collection) measurements are performed to quantify the surface-bound ${ }^{228} \mathrm{Th}$ (only one measurement to determine ${ }^{228} \mathrm{Th}$ is mandatory) (Cai et al., 2012, 2014, 2015).

\subsection{Efficiency of the RaDeCC System}

The efficiency of the RaDeCC counter for ${ }^{223} \mathrm{Ra}$ and ${ }^{224} \mathrm{Ra}$ measurements is usually calculated using single-tracer standards with known activities of ${ }^{227} \mathrm{Ac}$ (in radioactive equilibrium with ${ }^{223} \mathrm{Ra}$ ) and ${ }^{232} \mathrm{Th}$ 
Table 1

Definition of the Terms and Values Used in the Simulations. The Data From Background Measurements is Based on the Registered Data Analyses From Section 4.1. The Model Constants and the Values for the RaDeCC Counter Efficiencies are Based on Giffin et al. (1963), Moore and Arnold (1996), and Moore and Cai (2013)

\begin{tabular}{|c|c|c|c|}
\hline Term & Definition & Values & Units \\
\hline & Model constants & & \\
\hline$t_{D-219}$ & Delay time of 219 channel & 0.01 & $\mathrm{~ms}$ \\
\hline$t_{D-220}$ & Delay time of 220 channel & 5.61 & $\mathrm{~ms}$ \\
\hline$t_{G-219}$ & Gate time of 219 channel & 5.60 & $\mathrm{~ms}$ \\
\hline$t_{G-219}$ & Gate time of 220 channel & 600 & $\mathrm{~ms}$ \\
\hline$B K G_{\text {average }}$ & $\begin{array}{l}\text { Average background of the Total } \\
\text { channel }\end{array}$ & 2.24 & $\mathrm{cpm}$ \\
\hline \multirow[t]{2}{*}{$B K G_{S T D}$} & $\begin{array}{l}\text { Standard deviation background of the } \\
\text { Total channel }\end{array}$ & 1.38 & $\mathrm{cpm}$ \\
\hline & Efficiencies & & \\
\hline E 219 channel & Total efficiency of the 219 channel & 0.49 & \\
\hline E 220 channel & Total efficiency of the 220 channel & 0.54 & \\
\hline$E_{R a-226}$ & $\begin{array}{l}\text { Total efficiency for }{ }^{226} \mathrm{Ra} \\
\text { determination }\end{array}$ & 0.51 & \\
\hline$f_{S-219}$ & $\begin{array}{l}\text { Apparent system efficiency of the } 219 \\
\text { channel }\end{array}$ & 0.80 & \\
\hline$f_{S-220}$ & $\begin{array}{l}\text { Apparent system efficiency of the } 220 \\
\text { channel }\end{array}$ & 0.85 & \\
\hline$f_{C}$ & Apparent cell efficiency & 0.86 & \\
\hline$f_{E}$ & Emanation efficiency & 0.95 & \\
\hline$f_{G-219}$ & Gate efficiency of the 219 channel & 0.88 & \\
\hline$f_{G-220}$ & $\begin{array}{l}\text { Gate efficiency of the } 220 \text { channel } \\
\text { Simulation inputs }\end{array}$ & 0.91 & \\
\hline Initial ${ }^{223} R a$ & Simulated initial ${ }^{223} \mathrm{Ra}$ & & $\mathrm{cpm}$ \\
\hline Initial ${ }^{224} \mathrm{Ra}$ & Simulated initial ${ }^{224} \mathrm{Ra}$ & & $\mathrm{cpm}$ \\
\hline Initial ${ }^{226} \mathrm{Ra}$ & Simulated initial ${ }^{226} \mathrm{Ra}$ & & $\mathrm{cpm}$ \\
\hline \multirow[t]{2}{*}{ CT } & Counting time & & $\min$ \\
\hline & Simulation outputs & & \\
\hline 219 channel & Count rate of the 219 channel & & cpm \\
\hline 220 channel & Count rate of the 220 channel & & $\mathrm{cpm}$ \\
\hline Total channel & Count rate of the Total channel & & cpm \\
\hline Final219 & $\begin{array}{l}\text { Corrected } 219 \text { channel according } \\
\text { Moore and Arnold (1996) }\end{array}$ & & cpm \\
\hline \multirow[t]{2}{*}{ Final220 } & $\begin{array}{l}\text { Corrected } 220 \text { channel according } \\
\text { Moore and Arnold (1996) }\end{array}$ & & cpm \\
\hline & Channel ratios & & \\
\hline$C R_{220 / 219}$ & $\begin{array}{l}\text { Ratio between the channels } 220 \text { and } \\
219\end{array}$ & & \\
\hline$C R_{T O T / 220}{ }^{*}$ & $\begin{array}{l}\text { Ratio between the Total channel and } \\
\text { the first cycles of the } 220 \text { channel }\end{array}$ & & \\
\hline $\begin{array}{l}\left.C R_{(219}+220\right) / \\
\quad T O T\end{array}$ & $\begin{array}{l}\text { Ratio between the sum of the } 219 \text { and } \\
220 \text { channels and the Total channel }\end{array}$ & & \\
\hline
\end{tabular}

(in radioactive equilibrium with ${ }^{228} \mathrm{Th}$ and ${ }^{224} \mathrm{Ra}$ ) to calibrate the 219 channel (for ${ }^{223} \mathrm{Ra}$ ) and 220 channel (for ${ }^{224} \mathrm{Ra}$ ), respectively (Moore \& Cai, 2013; Scholten et al., 2010). The total efficiency for determining ${ }^{223} \mathrm{Ra}$ and ${ }^{224} \mathrm{Ra}$ activities is a function of (1) the fraction of the total decay events occurring within the scintillation cell (apparent system efficiency, $\left.f_{S}\right)$; (2) the fraction of alpha particles generated in the scintillation cell producing pulses that can be recorded by the photomultiplier tube (apparent cell efficiency, $f_{C}$ ); (3) the fraction of $\mathrm{Rn}$ that emanates from the sample (Mn-fiber, cartridge or sediment) (emanation efficiency, $f_{E}$ ); and (4) the fraction of Po events decaying between $t_{D}$ and $t_{D}+t_{G}$, where $t_{D}$ is the delay time and $t_{G}$ is the opening time of the electronic circuits (gate efficiency, $f_{G-219}$ and $f_{G-220}$ for 219 and 220 circuits, respectively).

The Total efficiency of the 219 and 220 circuits ( $E 219$ and $E 220$, respectively) can be theoretically calculated using equations 2 and 3, respectively (Giffin et al., 1963).

$$
\begin{aligned}
& E 219=f_{S-219} f_{C}^{2} f_{E} f_{G-219} . \\
& E 220=f_{S-220} f_{C}^{2} f_{E} f_{G-220} .
\end{aligned}
$$

Notice that for an Rn-Po coincident event the detector should record two alpha decays, and therefore, the cell efficiency is squared. Approximate values for these efficiencies are shown in Table 1 based on Giffin et al. (1963), Moore and Arnold (1996), and Moore and Cai (2013).

\section{Methods}

\subsection{Analysis of Registered Data}

$\mathrm{RaDeCC}$ measurements conducted in eight different laboratories worldwide (Table 2) from 2004 to 2018 have been gathered together $(\sim 17,000$ measurements) to obtain statistical information on the count rates and counting times commonly measured with the RaDeCC system. The RaDeCC output files (RaDeCC.SUM) were parsed using Python programming language and filtered in order to remove unreliable measurements (i.e., measurements with spurious counts induced by electrical surges, Moore, 2008) and background measurements. The applied data filters thus include only those measurements between counting times of 30 and 4,000 min and with activities higher than 0.01 and $0.1 \mathrm{cpm}$ for the 219 and 220 channels, respectively, and lower than $100 \mathrm{cpm}$ in the Total channel. The filtered data include measurements performed with the RaDeCC systems from different kind of samples (Mn-cartridges, Mn-fibers, sediments), including measurements of single- or mixed-tracer standards and collected in different environments (e.g., open ocean, coastal waters, and groundwaters). Notice that the applied data filters $(C T<30 \mathrm{~min})$ exclude not only most of the background measurements but also some potentially high ${ }^{224} \mathrm{Ra}$ activities measurements. The results from this analysis are used as reference values for the simulations presented in the following section (section 3.2).

\subsection{RaDeCC Simulations}

A set of simulations have been developed using Python programming language to reproduce the RaDeCC counting systematics in order to evaluate the effect of different 219, 220, and Total channel count rates in the quantification of ${ }^{223} \mathrm{Ra},{ }^{224} \mathrm{Ra},{ }^{226} \mathrm{Ra},{ }^{228} \mathrm{Ra},{ }^{228} \mathrm{Th}$, and ${ }^{227}$ Ac activities using the RaDeCC system. The simulations consist of two stages, which are detailed below: (1) the generation of a data set with the decay events that are registered by the RaDeCC depending on different initial activities of ${ }^{223} \mathrm{Ra},{ }^{224} \mathrm{Ra}$, and 
Table 2

Number of RaDeCC Measurements Performed by Different Laboratories Used for the Statistical Analysis

\begin{tabular}{llcc} 
& & Number of & Relative abundance \\
\cline { 4 - 4 } Lab name & Country & measurements & $\%$ \\
\hline${ }^{1}$ CEREGE & France & 574 & 3 \\
${ }^{2}$ IAEA-EL & Monaco & 725 & 4 \\
${ }^{3}$ ICBM & Germany & 1,479 & 9 \\
${ }^{4}$ UK & Germany & 2,967 & 18 \\
${ }^{5}$ LEGOS & France & 714 & 4 \\
${ }^{6}$ SUNY & US & 2,050 & 12 \\
${ }^{7}$ UAB & Spain & 8,096 & 48 \\
${ }^{8}$ WHOI & US & 301 & 2 \\
Total & & 16,906 & \\
\hline
\end{tabular}

${ }^{1}$ European Centre for Research and Teaching in Environmental Geosciences, Aix-Marseille University ${ }^{2}$ International Atomic Energy Agency - Environmental Laboratories of Monaco ${ }^{3}$ Grup of Microbiogeochemistry, School of Mathematics and Science, Institute for Chemistry and Biology of the Marine Environment ${ }^{4}$ Department of Sedimentology, Coastal and Shelf Research, Institute of Geosciences, University of Kiel ${ }^{5}$ Observatoire Midi Pyrénées, Laboratoire d'Études en Géophysique et Océanographie Spatiales ${ }^{6}$ School of Marine and Atmospheric Sciences, Stony Brook University ${ }^{7}$ Laboratori de Radioactivitat Ambiental, Universitat Autònoma de Barcelona ${ }^{8}$ Department of Marine Chemistry and Geochemistry, Woods Hole Oceanographic Institution
${ }^{226} \mathrm{Ra}$ and (2) the evaluation of the delayed coincidence system response to these activities. The definition of the terms and values used in the simulations is shown in Table 1, and all the simulation codes are available in supplementary material.

(1) A dataset consisting of a temporal vector with the decay events that occur during a single RaDeCC measurement is generated. This vector is used as an input file for the following simulation. From an initial arbitrary count rate of ${ }^{223} \mathrm{Ra},{ }^{224} \mathrm{Ra}$, and ${ }^{226} \mathrm{Ra}$ (see Table 3), the subsequent decay products of each decay chain (e.g., $\mathrm{Rn}, \mathrm{Po}, \mathrm{Pb}$, and $\mathrm{Bi}$ ) are randomly generated, following an exponential distribution according to their half-lives, and stored in individual lists. A specific vector is generated for each isotope and each selected initial count rate (based on the range of count rates obtained from the measurements described in section 3.1). The resulting lists are temporal single isotope vectors with a length equal to a certain counting time (also arbitrary; see Table 3) in which each decay event is located at a certain position within the vector. An additional list with background counts is created following a uniform distribution based on the average background measurements (and associated standard deviation) performed with the RaDeCC systems at the Universitat Autònoma de Barcelona (UAB) (Table 1). All the individual lists are added together into a final list, which contains the temporal position (within a certain counting time) of each alpha decay event produced in the simulated system.

(2) The delayed coincidence system is simulated in order to reproduce the count rates that would be produced within each channel of the RaDeCC system when specific initial count rates of ${ }^{223} \mathrm{Ra},{ }^{224} \mathrm{Ra}$, and ${ }^{226} \mathrm{Ra}$ are used as input data (input file obtained from the dataset described above). These simulations reproduce the counting mechanisms of the delayed coincidence system of the RaDeCC system, as presented by Moore and Arnold (1996). Analogous to the real RaDeCC system (section 2), after an initial simulated decay event at $t_{0}$, the subsequent events occurring between $\left[t_{0}+t_{D}\right]$ and $\left[\mathrm{t}_{0}+\mathrm{t}_{\mathrm{D}}+\mathrm{t}_{\mathrm{G}}\right]$ are counted in the respective circuits (219 or 220), as shown in Figure 1, where $t_{0}$ is the triggering event time, $t_{\mathrm{D}}$ is the delay time, and $t_{\mathrm{G}}$ is the gate time (Table 1 ). The outputs of these simulations include the count rates in the 219, 220, and Total channel (analogous to outputs from the RaDeCC system).

\subsection{Radium Sampling and Laboratory Experiments}

A set of measurements have been performed with the RaDeCC system to validate the detection limits derived from simulations. The samples used for this purpose were collected from an experimental site constructed in the lowest part of an alluvial aquifer at the Argentona ephemeral stream (NE of Barcelona, Spain) (Cerdà-Domènech et al., 2017) and in the Peníscola marshland (Castelló, Spain) (Rodellas et al., 2012). The collected water volumes $(\sim 120 \mathrm{~L})$ were filtered through Mn-fibers $(25 \mathrm{~g})$ at a controlled flow rate lower than $1 \mathrm{~L} \mathrm{~min}^{-1}$ to quantitatively extract Ra isotopes (Moore, 1976). After filtration, the fibers were rinsed with Ra-free deionized water in order to wash out any particles and sea salt. Before measurements, fibers were partially dried to a water-fiber ratio of 1:1 (Sun and Torgersen, 1998; Moore, 2008). Two experiments were

Table 3

Simulations Inputs for Sections 4.3, 4.4, 4.5, and 4.7

\begin{tabular}{|c|c|c|c|c|c|c|}
\hline Section & Simulations & $C T$ & Initial ${ }^{223} R a$ & Initial ${ }^{224} R a$ & Initial ${ }^{226} R a$ & $C R_{220 / 219}$ \\
\hline & \# & $\min$ & cpm & cpm & cpm & \\
\hline 4.3. Effect of high activity measurements $\left({ }^{223} \mathrm{Ra}\right)$ & 1,000 & 100 & $1-100$ & $0-200$ & $0-25$ & $0-2$ \\
\hline 4.3. Effect of high activity measurements $\left({ }^{224} \mathrm{Ra}\right)$ & 1,400 & 100 & $0-10$ & $0-100$ & $0-25$ & $10-20$ \\
\hline 4.4. Effect of $219-220$ cross-talk & 18,250 & 400 & $0-5$ & $0-25$ & $0-25$ & $0-250$ \\
\hline 4.5. Effect of ${ }^{222} \mathrm{Rn}$ buildup $\left({ }^{223} \mathrm{Ra}\right)$ & 2,600 & $200-1,000$ & $0.1-1.0$ & $0.1-2.0$ & $0-50$ & $0-4$ \\
\hline 4.5. Effect of ${ }^{222} \mathrm{Rn}$ buildup $\left({ }^{224} \mathrm{Ra}\right)$ & 1,400 & $200-1,000$ & $0.1-1.0$ & $0.1-2.0$ & $0-50$ & $10-20$ \\
\hline 4.7. Quantification of ${ }^{226} \mathrm{Ra}$ via ${ }^{222} \mathrm{Rn}$ buildup $\left({ }^{224} \mathrm{Ra}\right)$ & 360 & $10-1,400$ & 0.1 & $0-8$ & $0-470$ & 8 \\
\hline
\end{tabular}



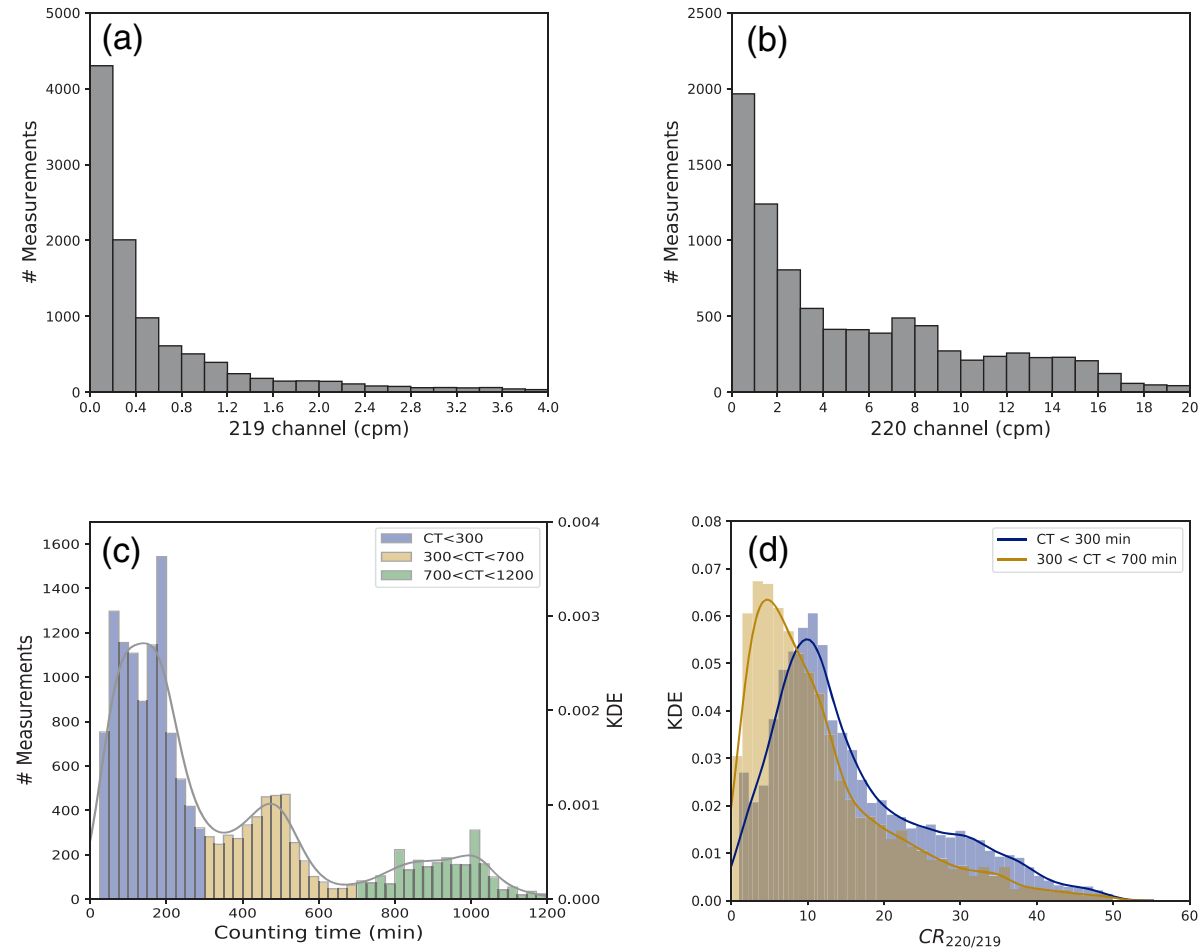

Figure 2. Histogram (a, b, and c) and kernel density estimate (KDE) (c and d) of 16,906 measurements performed by eight different laboratories between 2004 and 2018. (a) Count rate in the 219 channel $(30<\mathrm{CT}<800 \mathrm{~min}$ ). (b) Count rate in the 220 channel $\left(30<\mathrm{CT}<300 \mathrm{~min}\right.$ and $\left.C R_{220 / 219}>1\right)$. (c) Counting times. (d) $C R_{220 / 219}$. Blue, yellow, and green colors indicate counting times of $\mathrm{CT}<300,300<\mathrm{CT}<700$, and $700<\mathrm{CT}<1200$ min, respectively.

performed: The first experiment consisted on the reiterative measurement of a high activity ${ }^{223} \mathrm{Ra}$ and ${ }^{224} \mathrm{Ra}$ sample ( 20 and 1,600 dpm $100 \mathrm{~L}^{-1}$, respectively) over 39 days for the evaluation of the DCC under different count rates (due to the radioactive decay of ${ }^{223} \mathrm{Ra}$ and ${ }^{224} \mathrm{Ra}$ ). Then, the excess activities of ${ }^{223} \mathrm{Ra}\left({ }^{223} \mathrm{Ra} \mathrm{ax}_{\mathrm{x}}\right)$ and ${ }^{224} \mathrm{Ra}\left({ }^{224} \mathrm{Ra}_{\mathrm{ex}}\right)$ were quantified from each measurement; the second experiment consisted of measuring four high activity ${ }^{226} \mathrm{Ra}$ samples to evaluate the effect of ${ }^{222} \mathrm{Rn}$ buildup on the quantification of ${ }^{224} \mathrm{Ra}$ activities. For each measurement, the count rate registered in the 220 channel after each cycle ( $2 \mathrm{~min}$ ) was corrected following Moore and Arnold (1996).

\section{Results and Discussion}

\subsection{Analyses of Registered Data}

A statistical analysis of $\sim 17,000$ measurements performed with the RaDeCC system in different labs is represented in Figure 2. The distributions of the count rates registered in the 219 and 220 channels are shown in Figures $2 \mathrm{a}$ and $2 \mathrm{~b}$, respectively. Both distributions exhibit a maximum in the lowest range of count rates,

Table 4

Median Values of the 219, 220, Total Channel, and CR220/219 for the Characteristic Counting Times of the Histogram from Figure 2c

\begin{tabular}{lcccc}
\hline $\begin{array}{l}\text { Counting } \\
\text { time }\end{array}$ & $\begin{array}{c}219 \\
\text { channel }\end{array}$ & $\begin{array}{c}220 \\
\text { channel }\end{array}$ & $\begin{array}{c}\text { Total } \\
\text { channel }\end{array}$ & $\begin{array}{c}C R_{220 /} \\
219\end{array}$ \\
\hline $\min$ & cpm & cpm & cpm & \\
$30-300$ & 0.4 & 4.3 & 12.0 & 12.7 \\
$300-700$ & 0.2 & 1.1 & 4.7 & 8.9 \\
$700-1,200$ & 0.1 & 0.8 & 4.1 & 13.0 \\
$30-4,000$ & 0.2 & 1.9 & 7.2 & 11.5 \\
\hline
\end{tabular}

between 0.0 and $0.2 \mathrm{cpm}$ for the 219 channel and between 0 and $2 \mathrm{cpm}$ for the 220 channel. The median values for the 219, 220, and Total channels are $0.2,1.9$, and $7.2 \mathrm{cpm}$, respectively (Table 4).

The distribution of the counting times (Figure 2c) is characterized by three peaks that are consistent with the standard measurement procedure of the RaDeCC system described by Moore (2008). According to this procedure, to determine ${ }^{223} \mathrm{Ra}$ and ${ }^{224} \mathrm{Ra}$ activities, a first run is conducted shortly after sample collection (1-5 days). These measurements frequently present higher ${ }^{223} \mathrm{Ra}$ and ${ }^{224} \mathrm{Ra}$ activities and lower counting times relative to the measurements commonly used to determine ${ }^{227} \mathrm{Ac},{ }^{228} \mathrm{Th}$, or ${ }^{226} \mathrm{Ra}$. The first peak (between 30 and $300 \mathrm{~min}$ ) is consistent with these 

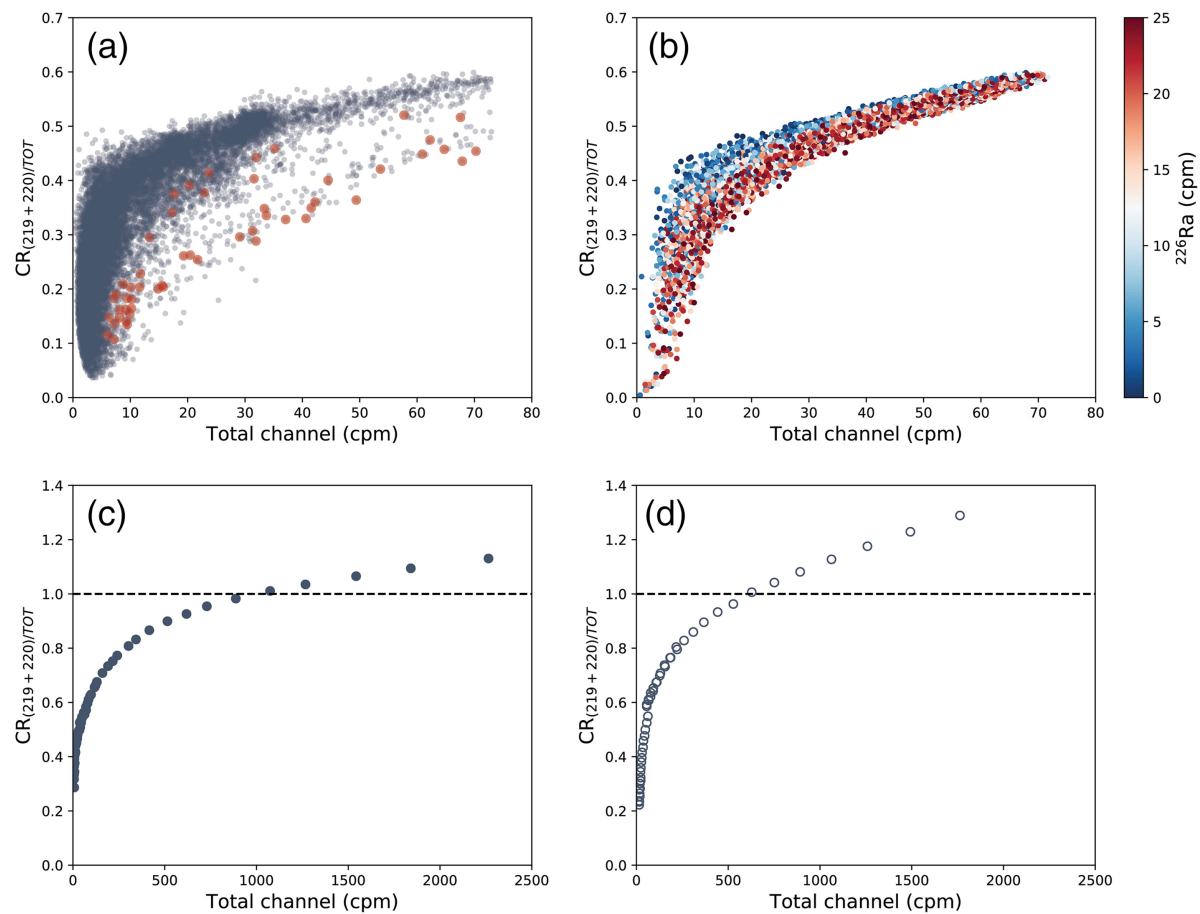

Figure 3. Relationship between the ratio $C R_{220 / 219}$ and the count rate in the Total channel. (a) Data from 16,906 measurements performed by eight different laboratories between 2004 and 2018. Red dots represent a set of high activity ${ }^{226}$ Ra measurements (Rodellas et al., 2012). (b) Simulations $(n=18,250)$ with initial ${ }^{223} \mathrm{Ra},{ }^{224} \mathrm{Ra}$, and ${ }^{226} \mathrm{Ra}$ count rates ranging $0-5,0-25$, and $0-25 \mathrm{cpm}$, respectively. The color scale represents the simulated initial ${ }^{226} \mathrm{Ra}$ count rate. (c) Data from the reiterative measurement of a high ${ }^{223} \mathrm{Ra}$ and ${ }^{224} \mathrm{Ra}$ sample $\left(20\right.$ and $1,600 \mathrm{dpm} 100 \mathrm{~L}^{-1}$, respectively). (d) Simulations ( $n=51$ ) with initial ${ }^{223} \mathrm{Ra},{ }^{224} \mathrm{Ra}$, and ${ }^{226} \mathrm{Ra}$ count rates ranging $0-250,0-1,500$, and $200 \mathrm{cpm}$, respectively.

initial measurements presenting the highest median count rates in all the channels $(0.4,4.3$, and $12.0 \mathrm{cpm}$ for 219, 220, and Total channels, respectively). The second peak, between 300 and 700 min, presents lower count rates in the 219,220 , and Total channels $(0.2,1.1$, and, $4.7 \mathrm{cpm}$, respectively) and a lower median value of the ratio between channels 220 and $219\left(C R_{220 / 219}\right)$ relative to the first peak as shown in Figure 2 d. This could be attributed to those measurements performed in order to determine ${ }^{223} \mathrm{Ra}$ activities when first runs presented high count rates in the 220 channel. In such cases, samples are measured again to allow ${ }^{224} \mathrm{Ra}$ to partially decay thereby reducing the channel ratio $C R_{220 / 219}$. Finally, due to the combination of high counting times (between 700 to 1,200) and low count rates $(0.1,0.8$, and, $4.1 \mathrm{cpm}$ for 219, 220, and Total channels, respectively), the third peak is associated with measurements of samples with low activities of ${ }^{223} \mathrm{Ra}$ and ${ }^{224} \mathrm{Ra}$, generally used to determine ${ }^{227} \mathrm{Ac},{ }^{228} \mathrm{Th}$, or ${ }^{226} \mathrm{Ra}$ (Table 4). According to the data registered in the eight laboratories, the range of initial ${ }^{223} \mathrm{Ra}$ and ${ }^{224} \mathrm{Ra}$ count rates used for the simulations in sections 4.4 and 4.5 (0-5 and 0-25 cpm for ${ }^{223} \mathrm{Ra}$ and ${ }^{224} \mathrm{Ra}$, respectively)covers approximately 95\% of the RaDeCC measurements.

\subsection{Systematics of the Delayed Coincidence Circuit}

The delayed coincidence circuit (DCC) of the RaDeCC system is designed to differentiate between the decay products of ${ }^{223} \mathrm{Ra}$ and ${ }^{224} \mathrm{Ra}$. As explained in section 2, when a first signal is registered, the 219 and 220 gates are opened after a certain delay time. Any event occurring within the opening time of both gates will be recorded in the corresponding channel according to the time elapsed between the triggering and subsequent events (Figure 1). The functioning of the DCC can be explored using the ratio between the sum of the 219 and 220 channels and the Total channel $\left(C R_{(219+220) / T O T}\right)$. In the optimal case, an initial decay of Rn triggers the circuit and is registered in the Total channel, and the second decay (Po) is registered in the 219 or 220 channels, as well as in the Total channel, producing a ratio $\left.C R_{(219}+220\right) / T O T=0.5$. Figure 3 shows the behavior of this ratio for real data (Figures $3 \mathrm{a}$ and $3 \mathrm{c}$ ) 
and simulations (Figures $3 \mathrm{~b}$ and $3 \mathrm{~d}$ ). Both real and simulated data likely present the same behavior, showing an increase of the ratio $\left.C R_{(219}+220\right) / T O T$ as the Total channel count rate increases, which is linked to an increase of short-lived Ra isotopes activities. Higher activities of ${ }^{223} \mathrm{Ra}$ and ${ }^{224} \mathrm{Ra}$ cause the 219 and 220 circuits to be triggered more frequently, thereby increasing the fraction of "on" time (i.e., the fraction of time in which the gates are open). This increase of Ra activities produces $\left.C R_{(219}+220\right) / T O T$ higher than 0.5 as a consequence of (1) channel multiregistration and/or (2) concurrent registration of a single event in both channels. The channel multiregistration occurs when, after a triggering event, two (or more) subsequent events take place within the opening time of a specific circuit. Multiregistration leads to an asymptotic increase of the channel ratio $C R_{(219+220) / T O T}$ to the value of 1 . For high counting rates in the Total channel $(>1,000 \mathrm{cpm})$, ratios above 1 are produced due to the effect of concurrent registration (Figures $3 c$ and d). The concurrent registration is the result of the independent behavior of the circuits from the DCC (Moore \& Arnold, 1996). Both circuits can be triggered by different events, and therefore, they can be open at the same time. Hence, if a decay event is produced when both circuits are open, the same event is registered in the Total channel and in both the 219 and 220 channels concurrently. In contrast with the multiregistration effect, which can be corrected by using the equations developed by Giffin et al. (1963), there is no protocol to correct the effect of the concurrent registration. Therefore, ${ }^{223} \mathrm{Ra}$ and ${ }^{224} \mathrm{Ra}$ activities cannot be appropriately quantified using the RaDeCC system when the influence of concurrent registration may significantly affect the results (i.e., in high activity samples). In section 4.3, we explore the limits of the applicability of the RaDeCC system and the appropriateness of the equations used to quantify ${ }^{223} \mathrm{Ra}$ and ${ }^{224} \mathrm{Ra}$ activities for high activity samples.

High activities of ${ }^{226} \mathrm{Ra}$ can also significantly influence the channel ratio $C R_{(219+220) / T O T}$ (Figure $3 \mathrm{~b}$ ) due to the ingrowth of ${ }^{222} \mathrm{Rn}$ (daughter of ${ }^{226} \mathrm{Ra}$ ) during the counting time. When a decay event of ${ }^{222} \mathrm{Rn}$ occurs, the delayed coincidence circuit is triggered, but its daughter $\left({ }^{218} \mathrm{Po}\right)$ will probably not decay within the opening times of the 219 and 220 gates due to its "longer" half-life (3.04 min). It will decay instead most likely after the gates are closed and therefore trigger the circuit again. Thus, $\left.C R_{(219}+220\right) / T O T$ decreases as the ${ }^{224} \mathrm{Ra} /{ }^{226} \mathrm{Ra}$ activity ratio decreases (Figure $3 \mathrm{~b}$ ). An example of this process is shown in Figure 3a, where a set of samples collected in Peníscola marshland (Castelló, Spain) (Rodellas et al., 2012) characterized by extremely low ${ }^{224} \mathrm{Ra} /{ }^{226} \mathrm{Ra}$ activity ratios $(<0.1)$ are highlighted in red.

\subsection{Effect of High Activity Measurements}

In this section, we evaluate the reliability of using the count rate of the 219 and 220 channels and the correction equations proposed by Moore and Arnold (1996) to quantify the activities of ${ }^{223} \mathrm{Ra}$ and ${ }^{224} \mathrm{Ra}$ when measuring high activity samples with the RaDeCC system. To do so, a set of simulations was performed to assess the ${ }^{223} \mathrm{Ra}$ and ${ }^{224} \mathrm{Ra}$ quantification limits. For both ${ }^{223} \mathrm{Ra}$ and ${ }^{224} \mathrm{Ra}$, the ratio between Initial ${ }^{223} \mathrm{Ra} /$ Initial ${ }^{224} R a$ was adjusted to avoid possible $219-220$ cross-talk following the limits provided in section 4.4 (Table 3).

In order to evaluate the quantification systematics, the ratio between the corrected channel count rate (Final219 or Final220) and the initial simulated count rate (Initial ${ }^{223} \mathrm{Ra}_{\text {or Initial }}{ }^{224} \mathrm{Ra}$, respectively) is a useful tool. Since the system $\left(f_{S}\right)$, cell $\left(f_{C}\right)$, and emanation efficiencies $\left(f_{E}\right)$ are not influencing the simulations, this ratio should equal the gate efficiency of the specific channel (0.88 for $f_{G-219}$ and 0.91 for $f_{G-220}$ ). Deviations of the simulated ratio (Final219/Initial ${ }^{223}$ Ra or Final220/Initial ${ }^{224} R a$ ) from the expected gate efficiency are thus indicative of the appropriateness of the quantification systematics and the corrections applied to account for chance coincidence and interferences between channels. Simulated ratios (Final219/Initial ${ }^{223} \mathrm{Ra}$ or Final220/Initial ${ }^{224} \mathrm{Ra}$ ) that deviate $>5 \%$ from the gate efficiency are indicative of erroneous quantification of $\mathrm{Ra}$ isotopes. We used $5 \%$ as a limit because this value corresponds to the minimum relative uncertainties that can be obtained for ${ }^{223} \mathrm{Ra}$ and ${ }^{224} \mathrm{Ra}$ measurements with the RaDeCC system (Garcia-Solsona et al., 2008).

The results of the simulations indicate that significant deviations ( $>5 \%)$ of the ratios Final219/ Initial ${ }^{223} \mathrm{Ra}$ and Final220/Initial ${ }^{224} \mathrm{Ra}$ relative to the gate efficiency $\left(f_{G-219}=0.88\right.$ and $f_{G-220}=0.91$, respectively) may occur for measurements with count rates in the Total channel above $200 \mathrm{cpm}$ for ${ }^{223} \mathrm{Ra}$ and $100 \mathrm{cpm}$ for ${ }^{224} \mathrm{Ra}$ (Figure 4). Above these count rates, the determination of triggering events 

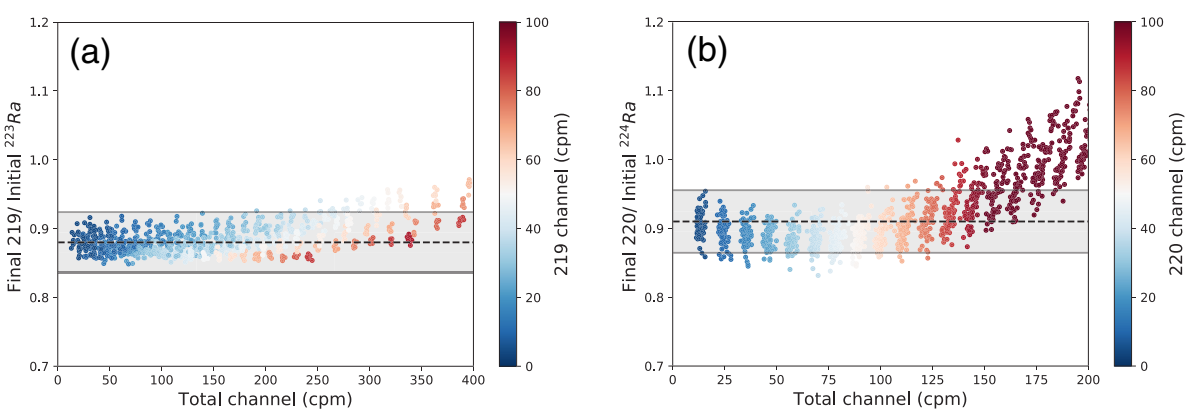

Figure 4. Results from simulations $(n=2,290)$ with initial ${ }^{223} \mathrm{Ra},{ }^{224} \mathrm{Ra}$, and ${ }^{226} \mathrm{Ra}$ count rates ranging 0-100, 0-100, and 0-25 cpm, respectively. (a) Ratio between corrected 219 channel and initial ${ }^{223}$ Ra simulated count rates (Final219/Initial ${ }^{223} \mathrm{Ra}$ ) against Total channel count rate. (b) Ratio Final220/Initial ${ }^{224} \mathrm{Ra}$ against Total channel count rate. The dashed line represents the gate efficiency $\left(f_{G}\right)$ and the gray band an uncertainty of $5 \%$. The color scale represents the count rate in the Total channel.

(cpmTot $-(\operatorname{cpm} 219+\operatorname{cpm} 220))$, which is necessary to apply the chance coincidence equations (see section 2), is underestimated due to the concurrent registration effect. This effect occurs when a single decay event is registered in both the 219 and 220 channels concurrently, as explained in section 4.2. Thus, the maximum quantification limits for ${ }^{223} \mathrm{Ra}$ and ${ }^{224} \mathrm{Ra}$ are 200 and $100 \mathrm{cpm}$ in the Total channel, respectively. Above these conservative limits, the equations proposed by Moore and Arnold (1996) to correct the chance coincidence events and the interactions between channels might produce erroneous quantifications of the ${ }^{223}$ Ra (i.e., Final219) and ${ }^{224}$ Ra (i.e., Final220) activities. Notice that the limit for the quantification of ${ }^{223} \mathrm{Ra}$ activities is higher than the limit for ${ }^{224} \mathrm{Ra}$ quantification. This is due to the lower relative importance of the chance coincidence on the count rate correction for the 219 channel relative to the 220 channel, since the opening time of the 219 circuit is two orders of magnitude lower relative to the 220 circuit (5.6 and $600 \mathrm{~ms}$, respectively). The median count rates in the Total channel for the data registered in different labs $(7.2 \mathrm{cpm})$ is two orders of magnitude lower than the calculated limits. Nevertheless, the maximum detection limits of the RaDeCC system must be taken into account, especially when measuring samples highly enriched in ${ }^{223} \mathrm{Ra}$ and ${ }^{224} \mathrm{Ra}$ (e.g., groundwater, pore waters, and water from brines). If the quantification limits are overpassed, an additional measurement should be performed after a certain time allowing the short-lived Ra isotopes to decrease in their activities.

\subsection{Effect of 219-220 Cross-Talk}

In this section, we evaluate the influence of different activities of Ra isotopes on the quantification of ${ }^{223} \mathrm{Ra}$ and ${ }^{224} \mathrm{Ra}$ and the accuracy of the corrections proposed by Moore and Arnold (1996) to correct 219-220 cross-talk interferences. In order to perform this analysis, a set of simulations was conducted with initial ${ }^{223} \mathrm{Ra},{ }^{224} \mathrm{Ra}$, and ${ }^{226} \mathrm{Ra}$ count rates of $0-5,0-25$, and $0-25 \mathrm{cpm}$, respectively, reproducing count rates from samples commonly measured with the RaDeCC system (see section 4.1).

Simulation results for the 219 channel (Figure 5a) show deviations of the ratio Final219/Initial ${ }^{223} R a$ from the gate efficiency $\left(f_{G-219}=0.88\right)$ that are mainly attributed to the influence of ${ }^{224} \mathrm{Ra}$ on the 219 channel (i.e., channel cross-talk). The effect of ${ }^{224} \mathrm{Ra}$ in the 219 channel is more evident in the lower range of Initial ${ }^{223} \mathrm{Ra}$ count rates $(0-0.5 \mathrm{cpm})$. Nevertheless, these deviations in relation to the 219 gate efficiency $\left(f_{G-219}\right)$ result from the combination of low Initial ${ }^{223} R a$ and high Initial ${ }^{224} R a(>20 \mathrm{cpm})$, which would exhibit extremely high ratios between 220 and 219 channels $\left(C R_{220 / 219}>40\right)$. It should be noted that these high $C R_{220 / 219}$ are not commonly measured in water samples (only $2.4 \%$ of registered data have $C R_{220 / 219}>40$; section 4.1), and most of them are associated with single-tracer standard (e.g., ${ }^{232} \mathrm{Th}$ ) measurements for the determination of the efficiency of 220 channel (section 4.1). For $C R_{220 / 219}<40$, the deviations range from $-6 \%$ to $38 \%$, which could represent up to eight times the minimum relative uncertainty of $5 \%$ (Garcia-Solsona et al., 2008). As shown in Figure 5b, high values of $C R_{220 / 219}$ correspond to a larger deviation between the ratio Final219/Initial ${ }^{223} R a$ and the gate efficiency (i.e., $f_{G-219}$ ), thus leading to a higher potential error on the quantification of ${ }^{223} \mathrm{Ra}$. Therefore, the results from this study suggest that the ${ }^{223} \mathrm{Ra}$ quantification might not be accurate (deviations larger than 5\%) when (1) $C R_{220 / 219}>10$ or (2) $C R_{220 / 219}>4$ and 220 

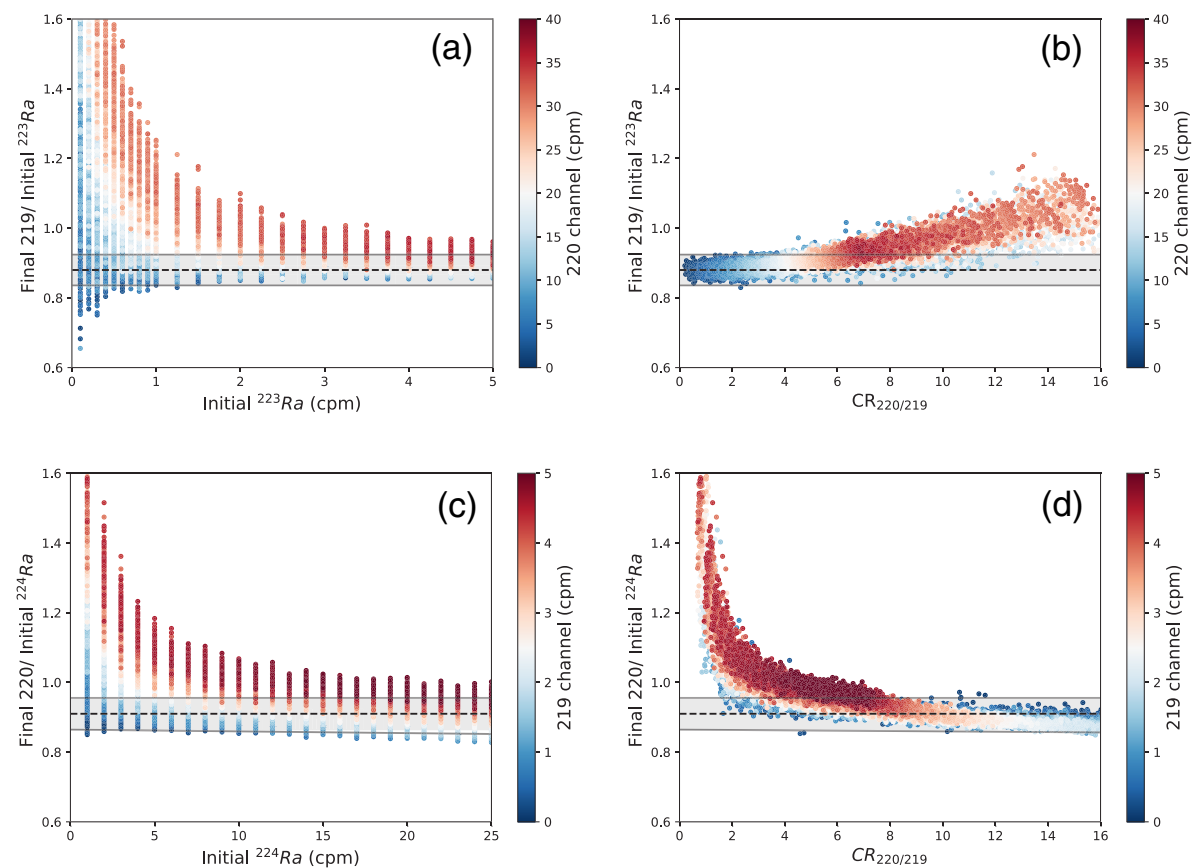

Figure 5. Results from simulations $(n=18,250)$ with initial ${ }^{223} \mathrm{Ra},{ }^{224} \mathrm{Ra}$, and ${ }^{226} \mathrm{Ra}$ count rates ranging $0-5,0-25$, and 0-25 cpm, respectively. The ratio between corrected 219 channel and initial ${ }^{223}$ Ra simulated count rates (Final219/ Initial $^{223} \mathrm{Ra}$ ) against (a) Initial ${ }^{223} \mathrm{Ra}$ and (b) $\mathrm{CR}_{220 / 219}$. The ratio Final220/Initial ${ }^{224} \mathrm{Ra}$ against (c) Initial ${ }^{224} \mathrm{Ra}$ and (d) $\mathrm{CR}_{220 / 219}$. Colors represent the 219 ( $\mathrm{a}$ and b) and 220 ( $\mathrm{c}$ and d) channels count rate. The dashed line represents the gate efficiency $\left(f_{G}\right)$ and the gray band an uncertainty of $5 \%$. Solid lines indicate the $\mathrm{CR}_{220 / 219}$ limits for quantification.

channel $>5 \mathrm{cpm}$. These results agree with the study of Scholten et al. (2010), where single- and mixed-tracer $\left({ }^{227} \mathrm{Ac}\right.$ and $\left.{ }^{228} \mathrm{Th}\right) \mathrm{Mn}$-fiber standards were prepared to calibrate the efficiencies of the RaDeCC system for ${ }^{223} \mathrm{Ra}$ and ${ }^{224} \mathrm{Ra}$. Scholten et al. (2010) suggested that samples with relatively high ${ }^{224} \mathrm{Ra}$ count rates (>7 cpm) may prevent a precise ${ }^{223} \mathrm{Ra}$ determination. Thus, samples with these characteristics should not be quantified to avoid an overestimation of the ${ }^{223} \mathrm{Ra}$ activities. Almost two-thirds $(65 \%)$ of the registered measurements from different labs examined in section 4.1 present these conditions, which would lead to an inappropriate quantification of ${ }^{223} \mathrm{Ra}$. However, it should be noted that most of these measurements were likely conducted shortly after the collection of the sample (when ${ }^{224} \mathrm{Ra}$ activities are usually high compared with ${ }^{223} \mathrm{Ra}$ ), and thus, they were most likely not used to quantify ${ }^{223} \mathrm{Ra}$ activities.

The influence of high ${ }^{223} \mathrm{Ra}$ activities also produces relevant deviations of the ratio Final220/Initial ${ }^{224} \mathrm{Ra}$ (Figure 5c) from the gate efficiency $\left(f_{G-220}=0.91\right)$. Measurements with $C R_{220 / 219}<1$ present the highest deviations, but they are not frequent in natural environments (only $3.6 \%$ of registered data have $C R_{220}$ / $219<1$ ), and most of them are associated with single-tracer standard measurements for 219 channel efficiency determination (e.g., ${ }^{227} \mathrm{Ac}$ ). For $C R_{220 / 219}>1$, the deviations in relation to the theoretical value (i.e., $f_{G-220}$ ) range from $-8 \%$ to $30 \%$ and tend to increase when $C R_{220 / 219}$ decreases. These deviations exceed $5 \%$ when (1) $C R_{220 / 219}<8$ and 219 channel $>1 \mathrm{cpm}$ or (2) $C R_{220 / 219}<2$ (Figure 5d). These two scenarios represent together $11 \%$ of the registered data from section 4.1 . If one of these cases is met, the ${ }^{224}$ Ra quantification should not be performed in order to avoid an overestimation of the ${ }^{224} \mathrm{Ra}$ activities.

The above recommendations, which are summarized in section 5, are also valid for the determination of ${ }^{227} \mathrm{Ac}$ and ${ }^{228} \mathrm{Th}$ activities with the RaDeCC system by measuring their daughters in radioactive equilibrium $\left({ }^{223} \mathrm{Ra}\right.$ and ${ }^{224} \mathrm{Ra}$, respectively). However, in this latter case, due to their low activities in water samples, proper statistical quantification of these isotopes requires long counting times (800-1,200 min; section 4.1) that can be highly influenced by the ${ }^{222} \mathrm{Rn}$ buildup from the decay of ${ }^{226} \mathrm{Ra}$ present in the fiber (Moore, 2008) (see section 4.5). Similarly, these recommendations apply to the determination of surface exchangeable ${ }^{224} \mathrm{Ra}$ and ${ }^{228} \mathrm{Th}$ from sediments. 

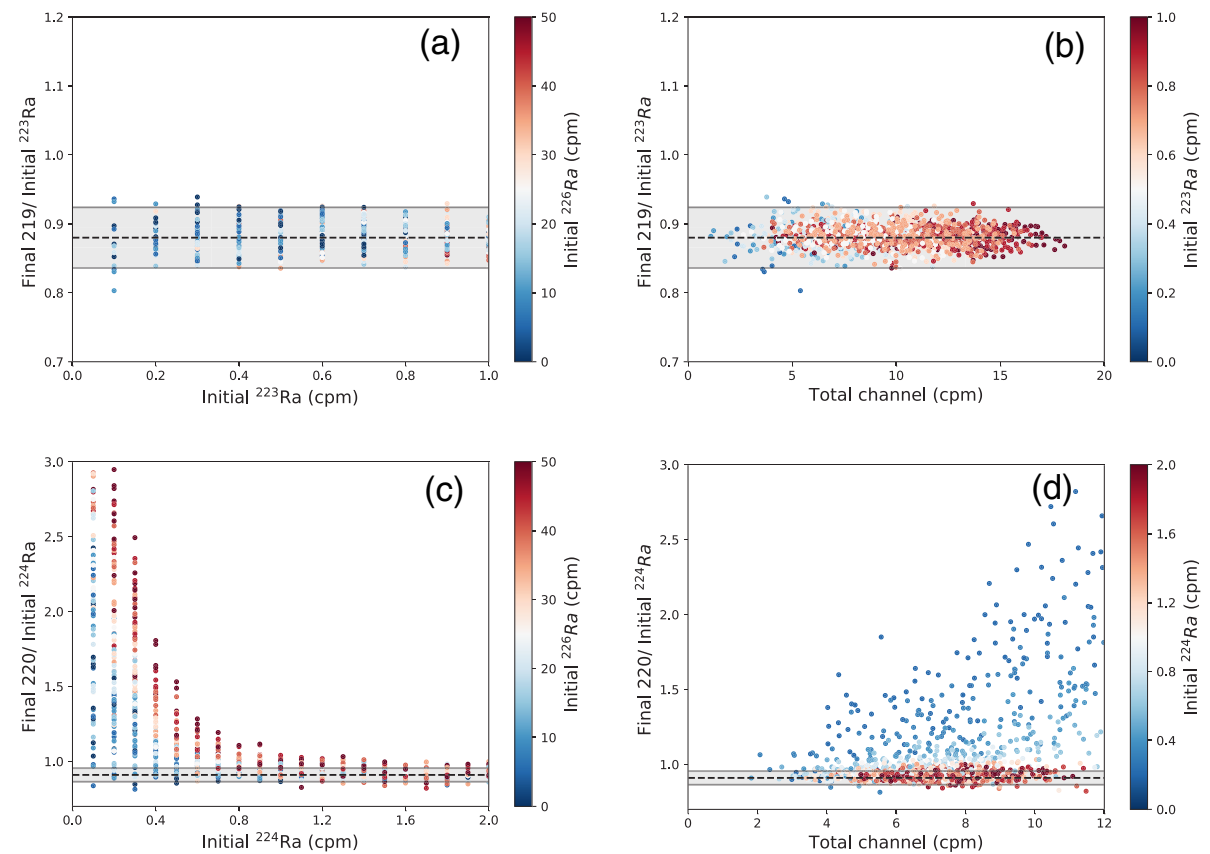

Figure 6. Results from simulations $(n=4,000)$ with initial ${ }^{223} \mathrm{Ra},{ }^{224} \mathrm{Ra}$, and ${ }^{226} \mathrm{Ra}$ count rates ranging $0.1-1.0,0.1-2.0$, and $0-50 \mathrm{cpm}$, respectively. The ratio between corrected 219 channel and initial ${ }^{223} \mathrm{Ra}$ simulated count rates (Final219/Initial ${ }^{223} \mathrm{Ra}$ ) against (a) Initial ${ }^{223} \mathrm{Ra}$ and (b) count rate in the Total channel. The ratio Final220/Initial ${ }^{224} \mathrm{Ra}$ against (c) Initial ${ }^{224} R a$ and (d) count rate in the Total channel. Colors represent the Initial ${ }^{226} R a$ count rates in (a) and (c), Initial ${ }^{223} R a$ in (b), and Initial ${ }^{224} R a$ in (d). The dashed line represents the gate efficiency $\left(f_{G}\right)$ and the gray band an uncertainty of $5 \%$.

\subsection{Effect of ${ }^{222} \mathrm{Rn}$ Buildup}

The buildup of ${ }^{222} \mathrm{Rn}$ from the decay of ${ }^{226} \mathrm{Ra}$ produces a continuous increase of the count rate in the Total channel (see section 4.2) that could lead to an erroneous correction of the 219 and 220 channel count rates (Moore, 2008). This effect would especially influence those measurements with low ${ }^{223} \mathrm{Ra}$ and ${ }^{224} \mathrm{Ra}$ activities $(<2 \mathrm{cpm})$, commonly used to determine the activities of ${ }^{227} \mathrm{Ac}$ and ${ }^{228} \mathrm{Th}$, mainly because they require long counting times ( $>200$ minutes) to obtain 400 counts in the respective channel ( $5 \%$ relative uncertainty). In this section, we evaluate the effect of ${ }^{222} \mathrm{Rn}$ buildup through a set of simulations that reproduces characteristic measurements to determine ${ }^{227} \mathrm{Ac}$ and ${ }^{228} \mathrm{Th}$ activities (low activities and long counting times; section 4.1). The simulated initial ${ }^{223} \mathrm{Ra},{ }^{224} \mathrm{Ra}$, and ${ }^{226} \mathrm{Ra}$ count rates ranged between $0-1,0-2$, and $0-$ $50 \mathrm{cpm}$, respectively (Table 3 ). The counting time was set to 1,000 min for initial count rates below $0.4 \mathrm{cpm}$. For higher count rates, the counting time was adjusted to achieve 400 counts in the respective channel ( $5 \%$ relative uncertainty).

The variation of the ratio Final219/Initial ${ }^{223} \mathrm{Ra}$ for different Initial ${ }^{223} \mathrm{Ra}$ and count rates in the Total channel is shown in Figures $6 a$ and b, respectively. There are no significant deviations of this ratio relative to the gate efficiency $\left(f_{G-219}=0.88\right)$ for the simulated count rates (Initial ${ }^{226} R a$ up to $\left.50 \mathrm{cpm}\right)$, suggesting that due to the short opening time of the 219 circuit (5.6 ms), the influence of ${ }^{222} \mathrm{Rn}$ buildup in the 219 channel is almost negligible. Conversely, the influence of ${ }^{222} \mathrm{Rn}$ buildup in the 220 channel is significant due to its longer gate opening time (600 ms), producing significant increases of the ratio Final220/Initial ${ }^{224} \mathrm{Ra}$ with the increase of ${ }^{226} \mathrm{Ra}$ activities (Figure 6c). Regardless of the influence of the counting time (i.e., time for ${ }^{222} \mathrm{Rn}$ ingrowth), which was adjusted for this simulation to obtain an uncertainty of $5 \%$ in the ${ }^{224}$ Ra quantification, the main factors that determine the deviation of the ratio Final220/Initial ${ }^{224} \mathrm{Ra}$ are the activities of ${ }^{224} \mathrm{Ra}$ and ${ }^{226} \mathrm{Ra}$. For Initial ${ }^{224} \mathrm{Ra}$ count rates below $1 \mathrm{cpm}$, deviations of the ratio Final220/Initial ${ }^{224} \mathrm{Ra}$ from the gate efficiency $\left(f_{G-220}=0.91\right)$ increase significantly as the Total channel count rate increases (Figure $\left.6 \mathrm{~d}\right)$. A useful ratio for evaluating the possible overestimation due to ${ }^{222} \mathrm{Rn}$ buildup is the ratio between the count rate in 
the Total channel and the count rate in the 220 channel from the first cycles of the measurement $(<30$ min; low influence of ${ }^{222} \mathrm{Rn}$ buildup), defined here as $\mathrm{CR}_{\mathrm{TOT} / 220}{ }^{*}$. The results from these simulations suggest that ratios $\mathrm{CR}_{\mathrm{TOT} / 220}{ }^{*}$ above 12 may overestimate the ${ }^{224} \mathrm{Ra}$ activities. We thus propose that when a conservative threshold of $\mathrm{CR}_{\mathrm{TOT} / 220}{ }^{*}=12$ is overpassed, the counting should be stopped, and the sample purged before initializing again the measurement as recommended by (Moore, 2008).

\subsection{On the Use of the Total Channel to Quantify ${ }^{224}$ Ra Activities}

The activities of ${ }^{224} \mathrm{Ra}$ are usually quantified with the equations proposed by Moore and Arnold (1996). These equations were designed to correct the count rate in each channel by the chance coincident events and possible interferences between 219 and 220 circuits (i.e., cross-talk). However, for high activity samples ( $>10 \mathrm{cpm}$ in the Total channel), due to the relatively high effect of chance coincidence events $(>0.9 \mathrm{cpm}$ in the 220 channel), Moore (2008) suggested the use of the count rate in the Total channel to calculate ${ }^{224} \mathrm{Ra}$ activities. To do so, the count rate in the Total channel (corrected by subtracting the background) is divided by the apparent total system efficiency $\left(E_{T o t}\right)$, defined as the probability of recording a count following the decay of ${ }^{224} \mathrm{Ra}$ in the fiber (Moore, 2008). Finally, the simultaneously quantified ${ }^{223} \mathrm{Ra}$ activity is subtracted to compute the activity of ${ }^{224} \mathrm{Ra}$ (Eq. 3) as follows:

$$
{ }^{224} \mathrm{Ra}(\mathrm{dpm})=\frac{\text { Total channel }(\mathrm{cpm})-\text { background }(\mathrm{cpm})}{E \text { Tot }}-{ }^{223} \mathrm{Ra}(\mathrm{dpm}) .
$$

Nevertheless, using the Total channel to quantify ${ }^{224} \mathrm{Ra}$ implicitly assumes that all the counts are linked to Rn-Po decay events from ${ }^{224} \mathrm{Ra}$, with the only exception of the events related to background and ${ }^{223} \mathrm{Ra}$. However, as seen in sections 4.2 and 4.5, counts registered in the Total channel will be highly influenced by alpha decays related to ${ }^{226} \mathrm{Ra}$ (e.g. ${ }^{222} \mathrm{Rn},{ }^{218} \mathrm{Po}$, and ${ }^{214} \mathrm{Po}$ ), and thus, they cannot be corrected to quantify ${ }^{224} \mathrm{Ra}$ by simply subtracting the background and the ${ }^{223} \mathrm{Ra}$ activity. In addition, this method strongly depends on the quantification of the activity of ${ }^{223} \mathrm{Ra}$. As shown in section 4.4, the quantification of ${ }^{223} \mathrm{Ra}$ activities might be highly sensitive to the recorded ${ }^{224} \mathrm{Ra}$ activities and ${ }^{224} \mathrm{Ra} /{ }^{223} \mathrm{Ra}$ activity ratios. Inappropriate quantifications of ${ }^{223} \mathrm{Ra}$ activities will thus induce errors on the quantification of ${ }^{224} \mathrm{Ra}$ from the Total channel. Considering these two factors (influence of ${ }^{226} \mathrm{Ra}$ activities and potential inappropriate quantification of ${ }^{223} \mathrm{Ra}$ activity), we suggest avoiding the use of the Total channel count rate to quantify ${ }^{224} \mathrm{Ra}$ activities.

\subsection{Quantification of ${ }^{226} \mathrm{Ra}$ Via ${ }^{222} \mathrm{Rn}$ Buildup}

The buildup rate of ${ }^{222} \mathrm{Rn}$ from ${ }^{226} \mathrm{Ra}$ during a RaDeCC measurement can be used to determine ${ }^{226} \mathrm{Ra}$ activities. Geibert et al. (2013) used the chance coincidence equations proposed by Moore and Arnold (1996) to correct the count rate in the Total channel in order to reduce the effect of ${ }^{223} \mathrm{Ra}$ and ${ }^{224} \mathrm{Ra}$ in the determination of ${ }^{226} \mathrm{Ra}$. Nevertheless, as explained in the previous section (section 4.5) and as already mentioned by Moore (2008), the chance coincidence corrections would not properly correct the 219 and 220 channels under significant activities of ${ }^{226} \mathrm{Ra}(>10 \mathrm{cpm})$. Here, we propose an optimized method based on the original idea of Geibert et al. (2013), which enables the quantification of ${ }^{226} \mathrm{Ra}$ activities avoiding the use of the chance coincidence equations. The applicability of this method requires (1) long counting times (>600 min) to register a significant ingrowth of ${ }^{222} \mathrm{Rn}$ and (2) radioactive equilibrium of ${ }^{223} \mathrm{Ra}$ and ${ }^{224} \mathrm{Ra}$ with their direct parents $\left({ }^{227} \mathrm{Ac}\right.$ and ${ }^{228} \mathrm{Th}$, respectively) to avoid the decay of these isotopes during the measurement. Therefore, measurements for ${ }^{226}$ Ra determination should be performed 3 month after sample collection (or 1 month after collection if the ${ }^{223} \mathrm{Ra}$ activity is negligible).

To evaluate the relation between the Initial ${ }^{226} \mathrm{Ra}$ and the resulting Total channel count rate over time, a set of simulations was performed (values for the simulations are presented in Table 3). Figure 7 a shows the results of these simulations representing the characteristic slope of the Total channel count rate over time for different Initial ${ }^{226} \mathrm{Ra}$ count rates. This slope increases linearly with the increase of the Initial ${ }^{226} \mathrm{Ra}$ count rate (Figure $7 b$ ) with a slope/Initial ${ }^{226} R a$ conversion factor $(m)$ of $1.80 \pm 0.07 \cdot 10^{-4} \mathrm{~min}^{-1}$. Notice that the method does not require the equilibrium between ${ }^{222} \mathrm{Rn},{ }^{218} \mathrm{Po}$, and ${ }^{214} \mathrm{~Pb}$ since the conversion factor is calculated from the exponential ingrowth of ${ }^{222} \mathrm{Rn}$ (and its daughters), which is nearly linear for these relatively 

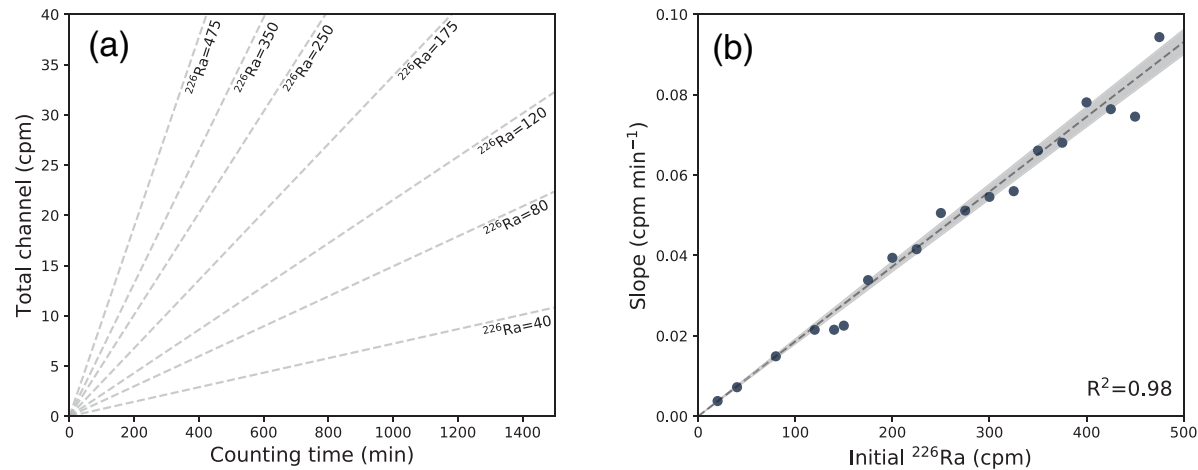

Figure 7. tResults from simulations $(n=360)$ with initial ${ }^{223} \mathrm{Ra},{ }^{224} \mathrm{Ra}$, and ${ }^{226} \mathrm{Ra}$ count rates ranging $0.1,0.8$, and $40-$ $475 \mathrm{cpm}$, respectively. (a) Characteristic ${ }^{222} \mathrm{Rn}$ buildup rate in the Total channel with counting time for different Initial $^{226} \mathrm{Ra}$ count rates. (b) Slopes of the characteristic ${ }^{222} \mathrm{Rn}$ buildup rate in the Total channel with counting time against Initial ${ }^{226} R a$. The dashed line represents the linear regression between slopes and Initial ${ }^{226} R a$.

short counting times (in comparison to ${ }^{222} \mathrm{Rn}$ half-life). Hence, we propose the following equations to quantify ${ }^{226} \mathrm{Ra}$ activities based on this conversion factor $(m)$ :

$$
\begin{aligned}
& \text { Initial }{ }^{226} R a(\mathrm{cpm})=\frac{\text { slope }\left(\mathrm{cpm} \cdot \mathrm{min}^{-1}\right)}{m\left(\mathrm{~min}^{-1}\right)}, \\
& { }^{226} R a \frac{\left(d p m L^{-1}\right)=\text { Initial }^{226} \mathrm{Ra}(\mathrm{cpm})}{E_{R a-226}\left(\mathrm{cpm} d p m^{-1}\right) V(L)},
\end{aligned}
$$

where Initial ${ }^{226} \mathrm{Ra}$ is the count rate of ${ }^{226} \mathrm{Ra}$ derived from the slope observed in the accumulative count rate of the Total channel (slope) during the measurement (RaDeCC output file: CPMTot) due to ${ }^{222} \mathrm{Rn}$ ingrowth and the conversion factor $\left(m=1.80 \pm 0.07 \cdot 10^{-4} \mathrm{~min}^{-1}\right) .{ }^{226} R a$ and $E_{R a-226}$ represent the activity of ${ }^{226} \mathrm{Ra}$ and the efficiency of the system for ${ }^{226} \mathrm{Ra}$ determination (described below), respectively. Notice that under low activities of ${ }^{226} \mathrm{Ra}$, the ${ }^{222} \mathrm{Rn}$ buildup may hardly develop and/or be associated with high uncertainties (Geibert et al., 2013). Therefore, we recommend the use of this method only for ${ }^{226} \mathrm{Ra}$ activities higher than

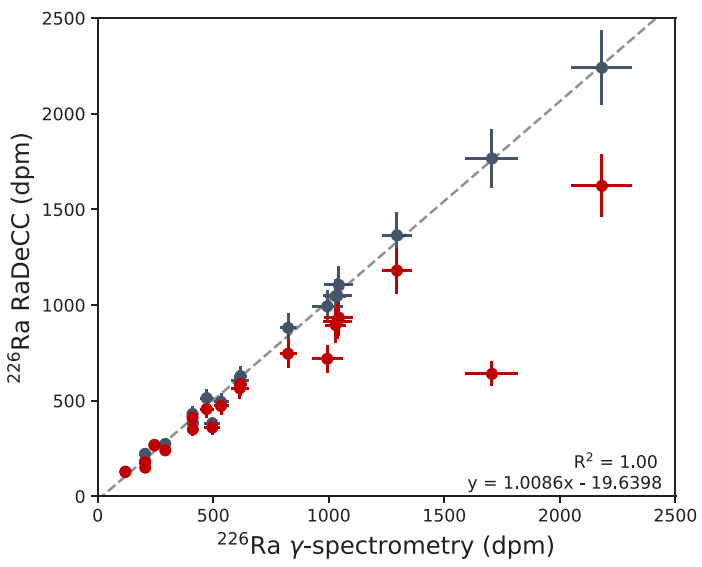

Figure 8. Intercomparison between the ${ }^{226} \mathrm{Ra}$ activities quantified via ${ }^{222} \mathrm{Rn}$ buildup with the RaDeCC system (blue dots, this study; red dots, Geibert et al. (2013)) and via $\gamma$-spectrometry from a set of samples collected in Peníscola marshland (Spain) (Rodellas et al., 2012). The dashed line represents the linear regression between ${ }^{226} \mathrm{Ra}$ activities quantified with the method presented in this paper and the activities quantified via $\gamma$-spectrometry.
$10 \mathrm{dpm}$, as initially suggested by Geibert et al. (2013). Another consideration must be taken into account before applying this method: During long measurements, besides the buildup of ${ }^{222} \mathrm{Rn}$ from ${ }^{226} \mathrm{Ra}$, significant amounts of ${ }^{212} \mathrm{Bi}$ and ${ }^{212} \mathrm{Po}$ due to ingrowth of ${ }^{212} \mathrm{~Pb}$ (from ${ }^{224} \mathrm{Ra}$ ) might be produced. Thus, the count rate in the total channel will be influenced by both, the ingrowth of ${ }^{222} \mathrm{Rn}$ (and daughters) and the ingrowth of ${ }^{212} \mathrm{~Pb}$ (and daughters), leading to wrong quantifications of ${ }^{226} \mathrm{Ra}$ activities. To minimize the effect of ${ }^{212} \mathrm{~Pb}$ ingrowth in the quantification, we recommend the use of this method when activities of ${ }^{224} \mathrm{Ra}\left({ }^{228} \mathrm{Th}\right)$ are below $1 \mathrm{cpm}$.

The reliability of this method was tested and compared with the method presented by Geibert et al. (2013) by using a set of ${ }^{226} \mathrm{Ra}$ samples collected in Peníscola marshland (Spain) (Rodellas et al., 2012) and analyzed via $\gamma$-spectrometry and RaDeCC (Figure 8). While both methods present a good correlation with the measurements performed via $\gamma$-spectrometry for ${ }^{226} \mathrm{Ra}$ activities ranging from 0 to $1000 \mathrm{dpm}$, the method presented by Geibert et al. (2013) exhibits higher deviations than the one presented in this work for activities higher than 1,000 dpm due to the erroneous corrections applied to the count rate in the Total channel.

The presented method has several advantages in relation to the previous one presented by Geibert et al. (2013): (1) The count rate in the Total 

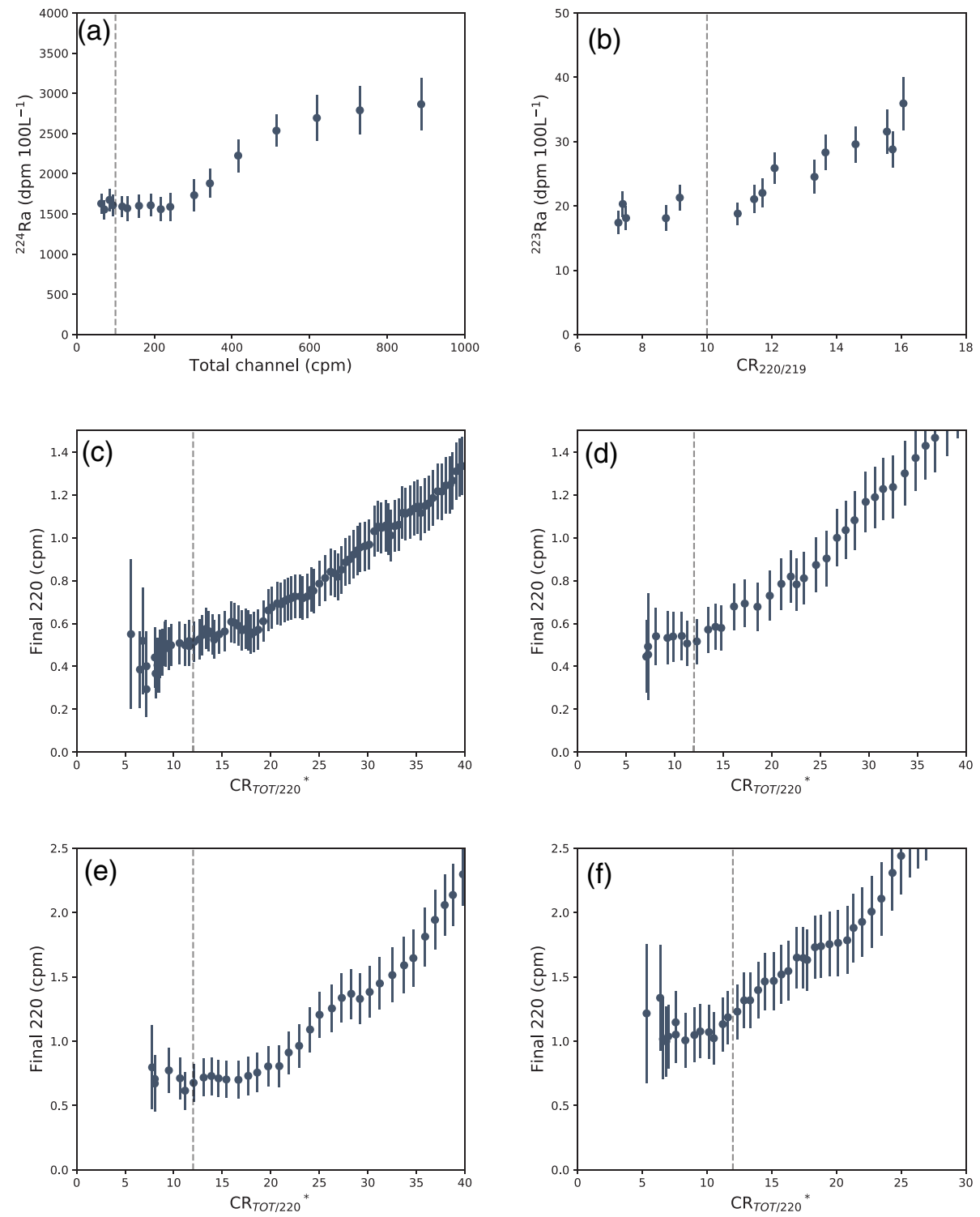

Figure 9. Compilation of measurements performed in the UAB laboratory. (a) Quantification of ${ }^{223} \mathrm{Ra}$ (b) and ${ }^{224} \mathrm{Ra}$ (a) against Total channel count rate and $C R_{220 / 219}$, respectively, from the repeated measurement of a high activity ${ }^{223}$ Ra and ${ }^{224} \mathrm{Ra}$ sample (20 and $1,600 \mathrm{dpm} 100 \mathrm{~L}^{-1}$, respectively). The Final220 count rate is evaluated in function of the Total channel count rate for four different measurements (c)-(f). The dashed lines indicate the quantification limits in cases of (a) high activity measurements, (b) $219-220$ cross-talk effect, and (c-f) ${ }^{222}$ Rn buildup effect.

channel is not corrected by chance coincidence in order to avoid erroneous quantifications for high ${ }^{226} \mathrm{Ra}$ activities (>1,000 dpm); (2) the relative uncertainties are slightly lower ( $>8 \%$ and $10 \%$, for this study and Geibert et al. (2013), respectively) because the mean error of the linear regression for the accumulative Total channel count rate over time is usually lower than the one for the corrected Total channel count rate used by Geibert et al. (2013), and (3) unlike the method proposed by Geibert et al. (2013), where several ${ }^{226} \mathrm{Ra}$ standards are needed to calculate the system efficiency, this method only requires the use of a single ${ }^{226} \mathrm{Ra}$ standard as described below.

\subsubsection{Calibration of the RaDeCC System for ${ }^{226}$ Ra Quantification}

In contrast with the efficiencies of the 219 and 220 channels, the efficiency to determine ${ }^{226} \mathrm{Ra}$ activities $\left(E_{R a-226}\right)$ only depends on the apparent system efficiency $\left(f_{S}\right)$ and the apparent cell efficiency $\left(f_{C}\right)$, because the Total channel is registering all the decay events (i.e., gate efficiency $\left(f_{G}\right)=1$ ), and the approach is based on the rate of ingrowth in the Total channel count rate (if the emanation efficiency $\left(f_{E}\right)$ is assumed to be 

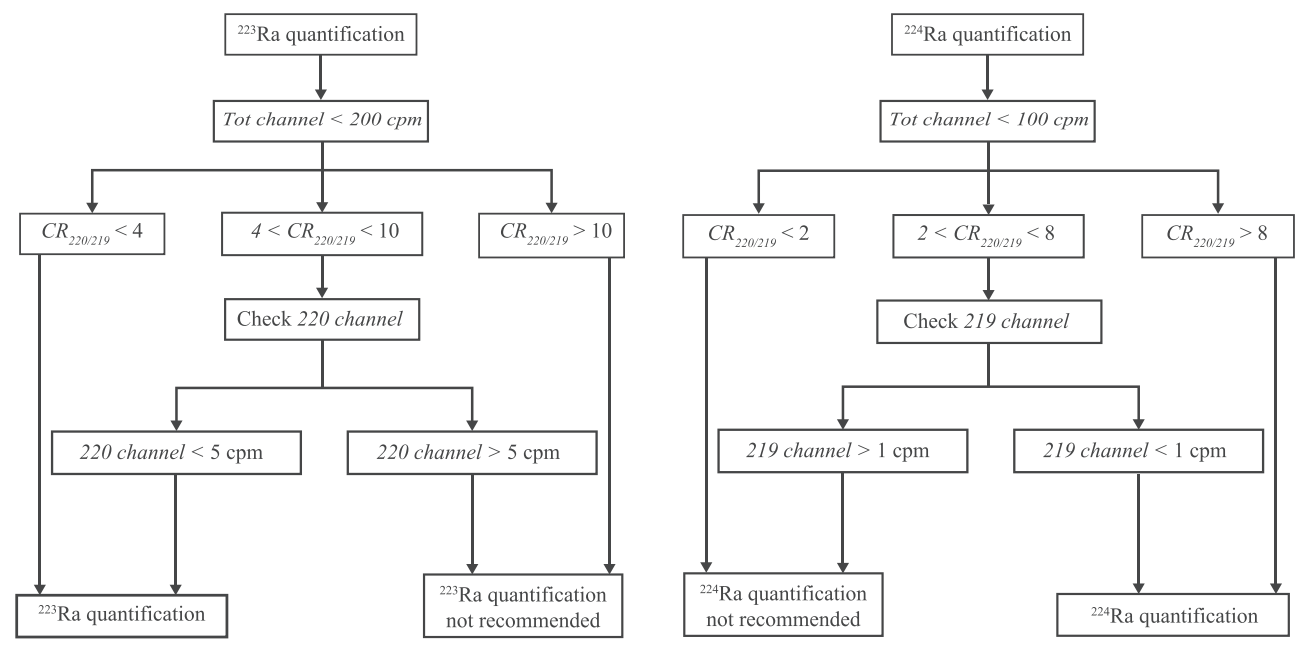

Figure 10. Schematic diagram of the guidelines to measure and quantify ${ }^{223} \mathrm{Ra}$ and ${ }^{224} \mathrm{Ra}$ samples with the RaDeCC system.

constant for the measurement, it will not affect the slope). The efficiency of the RaDeCC system to determine ${ }^{226} \mathrm{Ra}$ can thus be expressed as follows:

$$
E_{R a-226}=f_{S} f_{C}{ }^{3} \text {. }
$$

Notice that the apparent cell efficiency $\left(f_{C}\right)$ is raised to the power 3 in order to account for the three alpha decays $\left({ }^{222} \mathrm{Rn}^{2}{ }^{218} \mathrm{Po}^{-}{ }^{214} \mathrm{Po}\right)$ that subsequentially occur after an initial ${ }^{226} \mathrm{Ra}$ decay. The theoretical efficiency is 0.51 considering the values for $f_{C}$ and $f_{S}$ from Table 1 . However, the individual efficiencies for each RaDeCC system should be calculated by repeated measurements of standards with known activities of ${ }^{226}$ Ra.

\subsection{Testing the Quantification Limits With Laboratory Measurements}

In sections 4.3-4.5 we presented the limits for the quantification of ${ }^{223} \mathrm{Ra}$ and ${ }^{224} \mathrm{Ra}$ activities in case of high activity measurements, 219-220 cross-talk, and ${ }^{222} \mathrm{Rn}$ buildup effect, respectively. Here, some of these limits are tested with measurements performed with the RaDeCC system of the UAB laboratory (Figure 9). In section 4.3, we showed that the limit for the quantification of ${ }^{224} \mathrm{Ra}$ is $100 \mathrm{cpm}$ in the Total channel. Above this value, the quantification may overestimate the activities due to inappropriate correction of the count rate in the 220 channel. Considering that the limit provided in section 4.3 is conservative and may depend on different circumstances (e.g., counting time and activity ratios), the results from the reiterative measurements of a high activity sample are in good agreement with these limits (Figure 9a). The quantification of ${ }^{224} \mathrm{Ra}$ activities remains constant $\left(\sim 1,600 \mathrm{dpm} 100 \mathrm{~L}^{-1}\right)$ when the measurements perform count rates in the Total channel below $\sim 250 \mathrm{cpm}$. For measurements above $250 \mathrm{cpm}$ in the Total channel, the quantified activities increase up to $\sim 2,800 \mathrm{dpm} 100 \mathrm{~L}^{-1}$ (Figure 9a). Similarly, the different ${ }^{223}$ Ra quantifications of the same sample are also plotted against the ratio between 220 and 219 channel $\left(C R_{220 / 219}\right)$ at the time of measurement (Figure 9b). Above the ratio $C R_{220 / 219}>10$, the quantified activities of ${ }^{223}$ Ra increase from $\sim 20$ to $35 \mathrm{dpm} 100 \mathrm{~L}^{-1}$ as the $C R_{220 / 219}$ increases, in strong agreement with the limits presented in section 4.4. Finally, the limits presented in section 4.5 on the influence of ${ }^{222} \mathrm{Rn}$ buildup are investigated with four measurements of high activity ${ }^{226} \mathrm{Ra}$ samples (Figures $9 \mathrm{c}-\mathrm{f}$ ). The effect of ${ }^{222} \mathrm{Rn}$ buildup in the ${ }^{224} \mathrm{Ra}$ quantification is significant when the ratio between Total channel count rate and the count rate of the 220 channel from the first cycles is higher than $C R_{T O T / 220}{ }^{*}>12.9 \mathrm{c}-\mathrm{f}$

\section{Guidelines and Conclusions}

The Radium Delayed Coincidence Counter is one of the most widely used equipment for measuring ${ }^{223} \mathrm{Ra}$ and ${ }^{224} \mathrm{Ra}$ in water and sediment samples, and it is also frequently used to quantify ${ }^{227} \mathrm{Ac},{ }^{228} \mathrm{Th},{ }^{228} \mathrm{Ra}$, and ${ }^{226} \mathrm{Ra}$. In this study, we performed a detailed analysis of the counting systematics of the RaDeCC system through the analysis of recorded data from different laboratories and simulations in order to provide new 
guidelines on the use of the RaDeCC system. Together with the guidelines summarized below, two spreadsheets are provided for the quantification of (1) ${ }^{223} \mathrm{Ra}$ and ${ }^{224} \mathrm{Ra}$ activities and (2) ${ }^{226} \mathrm{Ra}$ activities.(supplementary material).

\subsection{Measurement and Quantification of ${ }^{223} \mathrm{Ra}$ and ${ }^{224} \mathrm{Ra}$ Activities}

The proper quantification of ${ }^{223} \mathrm{Ra}$ and ${ }^{224} \mathrm{Ra}$ activities using the RaDeCC system is highly dependent on (1) the count rate registered in the Total channel (section 4.3), (2) its channel ratio (220 channel/219 channel; $C R_{220 / 219}$ ) (section 4.4), and (3) the ${ }^{222} \mathrm{Rn}$ buildup (section 4.5). The ${ }^{222} \mathrm{Rn}$ buildup effect is treated in the following subsection since it is more significant for measurements that require long counting times (800-1,200 $\mathrm{min}$ ) due to the low activities of the samples (e.g., measurements for ${ }^{228} \mathrm{Th},{ }^{228} \mathrm{Ra}$, or ${ }^{227}$ Ac determination).

The quantification of ${ }^{223} \mathrm{Ra}$ activities should not be performed when the count rate in the Total channel overpasses $200 \mathrm{cpm}$ (section 4.3). For lower count rates, the quantification should be prevented to avoid 219-220 cross-talk interferences due to the influence of ${ }^{224} \mathrm{Ra}$ in the 219 channel when $C R_{220 / 219}>10$ or when $C R_{220 /}$ $219>4$ and 220 channel $>5 \mathrm{cpm}$ (see section 4.4). The quantification of ${ }^{223} \mathrm{Ra}$ under these conditions could produce an overestimation of the ${ }^{223} \mathrm{Ra}$ activities up to $\sim 40 \%$. When these conditions are met the quantification is not recommended. Then, a further measurement can be performed after a certain time to allow the $C R_{220 / 219}$ and the count rate in the 220 channel to decrease, as already recommended by Moore (2008).

The quantification of ${ }^{224} \mathrm{Ra}$ activities should never be derived from the Total channel count rate, as this channel is highly influenced by the activities of ${ }^{223} \mathrm{Ra}$ and ${ }^{226} \mathrm{Ra}$ (section 4.6), contrary to previous recommendation for high activity samples (Moore, 2008). Therefore, independent of the sample activity, the quantification of the ${ }^{224} \mathrm{Ra}$ activity should be based on the counting in the 220 channel and quantified using the equations proposed by Moore and Arnold (1996). To avoid inappropriate estimations, the quantification of ${ }^{224} \mathrm{Ra}$ activities with the RaDeCC system should be performed under both of the following conditions: (1) The count rate in the Total channel should be lower than the maximum quantification limit of $100 \mathrm{cpm}$ (section 4.3), and (2) the $C R_{220 / 219}$ should be higher than 8, or higher than 2 if 219 channel count rate does not exceed $1 \mathrm{cpm}$ (section 4.4). If the first condition is not met, further measurements can be performed to allow the activity of ${ }^{224} \mathrm{Ra}$ to decrease. Contrarily, if the second condition is not met, no extra measurements can be performed to increase $C R_{220 / 219}$, and the potential overestimation of the quantified ${ }^{224} \mathrm{Ra}$ activity (up to $30 \%$ ) should be acknowledged.

The thresholds and guidelines for an appropriate quantification of ${ }^{223} \mathrm{Ra}$ and ${ }^{224} \mathrm{Ra}$ activities using the RaDeCC system based on the results of this study are summarized in Figure 10.

\subsection{Measurement and Quantification of ${ }^{227} \mathrm{Ac}$ and ${ }^{228} \mathrm{Th}$ Activities}

The activities of ${ }^{227} \mathrm{Ac}$ and ${ }^{228} \mathrm{Th}$ are quantified with the RaDeCC system when their daughters $\left({ }^{223} \mathrm{Ra}\right.$ and ${ }^{224} \mathrm{Ra}$, respectively) are in radioactive equilibrium (i.e., after 1-3 months after sample collection), usually conducting long measurements to reduce the analytical uncertainty. In addition to the above-mentioned recommendations for ${ }^{223} \mathrm{Ra}$ and ${ }^{224} \mathrm{Ra}$, the quantification of ${ }^{227} \mathrm{Ac}$ and ${ }^{228} \mathrm{Th}$ activities will strongly depend on the buildup of ${ }^{222} \mathrm{Rn}$ from ${ }^{226} \mathrm{Ra}$ (section 4.5). In the case of ${ }^{227} \mathrm{Ac}\left({ }^{223} \mathrm{Ra}\right)$ quantification, this effect is negligible due to the short opening time of the 219 channel $\left(t_{G-219}=5.6 \mathrm{~ms}\right)$. Conversely, the ${ }^{222} \mathrm{Rn}$ buildup will significantly affect the ${ }^{228} \mathrm{Th}\left({ }^{224} \mathrm{Ra}\right)$ quantification (Figure $\left.6 \mathrm{~b}\right)$, especially for measurements with low counting rates in the 220 channel $(<1 \mathrm{cpm})$. In such cases, significant overestimations produced by ${ }^{222} \mathrm{Rn}$ buildup may occur when the ratio between the count rates in the Total channel and in the 220 channel from the first cycles $\left(C R_{T O T / 220}{ }^{*}\right)$ exceeds 12 (section 4.5$)$. In order to properly quantify ${ }^{224} \mathrm{Ra}$ or ${ }^{228} \mathrm{Th}$ activities under these specific conditions, the counting should be stopped when the threshold of $\mathrm{CR}_{\mathrm{TOT} / 220}{ }^{*}=12$ is overpassed (or only the first cycles of the measurement be used), and the sample should be properly purged before conducting a new measurement of the same sample (Moore, 2008).

\subsection{Measurement and Quantification of ${ }^{226} \mathrm{Ra}$ Activities via ${ }^{222} \mathrm{Rn}$ Buildup}

The activities of ${ }^{226} \mathrm{Ra}$ can be determined by using the ingrowth rate of ${ }^{222} \mathrm{Rn}$ in the Total channel using the

RaDeCC system. In this work, we propose an improved simple method to quantify ${ }^{226} \mathrm{Ra}$ activities based on this process and the approach described by Geibert et al. (2013). In contrast to the approach of Geibert 


\section{Acknowledgments}

The authors acknowledge the support from the Generalitat de Catalunya autonomous government through its funding schema to excellence research groups (grants 2017 SGR 1588 and 2014 SGR 1356) and the support from Spanish Government (projects CGL2013-48869-C2-1-R/2-R and CGL2016-77122-C2-1-576 R/2-R). We would like to thank all the people who contributed to this work sharing the data of their RaDeCC systems, including J. Scholten, C. Claude, M.A. Charette, J.K. Cochran, and R. Neuholz. We want to express our gratitude to our colleagues from the Laboratori de Radioactivitat Ambiental (Universitat Autònoma de Barcelona) and Dr. W. Geibert (AWI) for improving the quality of this work. A. Alorda-Kleinglass acknowledges financial support from ICTA "Unit of Excellence" (MinECo, MDM2015-0552-17-1)PhD fellowship, BES-2017-080740. Dr. V. Rodellas acknowledges financial support from the Beatriu de Pinós postdoctoral program of the Generalitat de Catalunya autonomous government (2017-BP-00334). P. van Beek thanks the support from ANR (MED-SGD project, ANR-15-CE01-0004). M. Diego-Feliu acknowledges the economic support from the FI-2017 fellowships of the Generalitat de Catalunya autonomous government (2017FI_B_00365). Compliance with AGU's DataPolicy: All the https://data. mendeley.com/datasets/jtct7mt8zr/2 codes and spreadsheets used in this article are provided online (supplementary material). et al. (2013), the method described in this study avoids correcting the count rate in the Total channel using the chance coincidence equations, since this correction may be inappropriate for high Ra activities (sections 4.2 and 4.7). The applicability of the method requires (1) long counting times (>600 $\mathrm{min}$ ) to register a significant ingrowth of ${ }^{222} \mathrm{Rn}$; (2) radioactive equilibrium between ${ }^{223} \mathrm{Ra}^{227} \mathrm{Ac}$ and ${ }^{224} \mathrm{Ra}^{228} \mathrm{Th}$; and (3) the calibration of the RaDeCC system with the use of a single ${ }^{226} \mathrm{Ra}$ standard. The activities of ${ }^{226} \mathrm{Ra}$ can be easily calculated by dividing the slope of the count rate in the Total channel over time by the conversion factor $\left(1.80 \pm 0.07 \cdot 10^{-4} \mathrm{~min}^{-1}\right.$; Figure $\left.7 \mathrm{~b}\right)$ and the efficiency of the counter for ${ }^{226} \mathrm{Ra}$.

\section{References}

Alorda-Kleinglass, A., Garcia-Orellana, J., Rodellas, V., Cerdà-Domènech, M., Tovar-Sánchez, A., Diego-Feliu, M., et al. (2019). Remobilization of dissolved metals from a coastal mine tailing deposit driven by groundwater discharge and porewater exchange. Science of the Total Environment, 688, 1359-1372. https://doi.org/10.1016/j.scitotenv.2019.06.224

Burnett, W. C., Aggarwal, P. K., Aureli, A., Bokuniewicz, H., Cable, J. E., Charette, M. A., et al. (2006). Quantifying submarine groundwater discharge in the coastal zone via multiple methods. Science of the Total Environment, 367(2-3), 498-543. https://doi.org/10.1016/j. scitotenv.2006.05.009

Cai, P., Shi, X., Hong, Q., Li, Q., Liu, L., Guo, X., \& Dai, M. (2015). Using ${ }^{224}$ Ra $/{ }^{228}$ Th disequilibrium to quantify benthic fluxes of dissolved inorganic carbon and nutrients into the Pearl River Estuary. Geochimica et Cosmochimica Acta, 170, 188-203. https://doi.org/10.1016/j. gca.2015.08.015

Cai, P., Shi, X., Moore, W. S., \& Dai, M. (2012). Measurement of ${ }^{224} \mathrm{Ra}:{ }^{228}$ Th disequilibrium in coastal sediments using a delayed coincidence counter. Marine Chemistry, 138-139, 1-6. https://doi.org/10.1016/j.marchem.2012.05.004

Cai, P., Shi, X., Moore, W. S., Peng, S., Wang, G., \& Dai, M. (2014). ${ }^{224}$ Ra: ${ }^{228}$ Th disequilibrium in coastal sediments: Implications for solute transfer across the sediment-water interface. Geochimica et Cosmochimica Acta, 125, 68-84. https://doi.org/10.1016/j.gca.2013.09.029

Cerdà-Domènech, M., Rodellas, V., Folch, A., \& Garcia-orellana, J. (2017). Constraining the temporal variations of Ra isotopes and Rn in the groundwater end-member: Implications for derived SGD estimates. Science of the Total Environment, 595, 849-857. https://doi.org/ 10.1016/j.scitotenv.2017.03.005

Charette, M. A., Henderson, P. B., Breier, C. F., \& Liu, Q. (2013). Submarine groundwater discharge in a river-dominated Florida estuary. Marine Chemistry, 156, 3-17. https://doi.org/10.1016/j.marchem.2013.04.001

Garcia-Orellana, J., Cochran, J. K., Bokuniewicz, H., Daniel, J. W. R., Rodellas, V., \& Heilbrun, C. (2014). Evaluation of ${ }^{224}$ Ra as a tracer for submarine groundwater discharge in Long Island sound (NY). Geochimica et Cosmochimica Acta, 141, 314-330. https://doi.org/10.1016/ j.gca.2014.05.009

Garcia-Solsona, E., Garcia-Orellana, J., Masqué, P., \& Dulaiova, H. (2008). Uncertainties associated with ${ }^{223}$ Ra and ${ }^{224}$ Ra measurements in water via a delayed coincidence counter (RaDeCC). Marine Chemistry, 109(3-4), 198-219. https://doi.org/10.1016/j. marchem.2007.11.006

Geibert, W., Annett, A., van Beek, P., Garcia-orellana, J., Hsieh, Y., \& Masque, P. (2013). ${ }^{226}$ Ra determination via the rate of ${ }^{222}$ Rn ingrowth with the radium delayed coincidence counter (RaDeCC). Limnology and Oceanography: Methods, 11, 594-603. https://doi.org/10.4319/ lom.2013.11.594

Giffin, C., Kaufman, A., \& Broecker, W. (1963). Delayed coincidence counter for the assay of actinon and thoron. Journal of Geophysical Research, 68(6), 1749-1757. https://doi.org/10.1029/JZ068i006p01749

Gonneea, M. E., Mulligan, A. E., \& Charette, M. A. (2013). Seasonal cycles in radium and barium within a subterranean estuary: Implications for groundwater derived chemical fluxes to surface waters. Geochimica et Cosmochimica Acta, 119, 164-177. https://doi. org/10.1016/j.gca.2013.05.034

Hong, Q., Cai, P., Geibert, W., \& Cao, Z. (2018). Benthic fluxes of metals into the Pearl River Estuary based on ${ }^{224} \mathrm{Ra} /{ }^{228} \mathrm{Th}$ disequilibrium: From alkaline earth (Ba) to redox sensitive elements (U, Mn, Fe). Geochimica et Cosmochimica Acta, 237, 223-239. https://doi.org/ 10.1016/j.gca.2018.06.036

Knee, K. L., Garcia-Solsona, E., García-Orellana, J., Boehm, A. B., \& Paytan, A. (2011). Using radium isotopes to characterize water ages and coastal mixing rates: A sensitivity analysis. Limnology and Oceanography: Methods, 9, 380-395. https://doi.org/10.4319/ lom.2011.9.380

Le Roy, E., Sanial, V., Lacan, F., van Beek, P., Souhaut, M., Charette, M. A., \& Henderson, P. B. (2019). Insight into the measurement of dissolved ${ }^{227} \mathrm{Ac}$ in seawater using radium delayed coincidence counter. Marine Chemistry, 212, 64-73. https://doi.org/10.1016/j. marchem.2019.04.002

Moise, T., Starinsky, A., Katz, A., \& Kolodny, Y. (2000). Ra isotopes and Rn in brines and ground waters of the Jordan-Dead Sea Rift Valley: Enrichment, retardation, and mixing. Geochimica et Cosmochimica Acta, 64(14), 2371-2388. https://doi.org/10.1016/S0016-7037(00) 00369-0

Moore, W. S. (1976). Sampling ${ }^{228} \mathrm{Ra}$ in the deep ocean. Deep-Sea Research and Oceanographic Abstracts, 23(7), 647-651. https://doi.org/ 10.1016/0011-7471(76)90007-3

Moore, W. S. (2000). Ages of continental shelf waters determined from ${ }^{223}$ Ra and ${ }^{224}$ Ra. Journal Geophysical Research, 105(C9), 117-122. https://doi.org/10.1029/1999JC000289

Moore, W. S. (2008). Fifteen years experience in measuring ${ }^{224} \mathrm{Ra}$ and ${ }^{223} \mathrm{Ra}$ by delayed-coincidence counting. Marine Chemistry, 109(3-4), 188-197. https://doi.org/10.1016/j.marchem.2007.06.015

Moore, W. S., \& Arnold, R. (1996). Ra in coastal waters using a delayed coincidence counter. Journal of Geophysical Research, 101(C1), 1321. https://doi.org/10.1029/95JC03139

Moore, W. S., Beck, M., Riedel, T., Rutgers van der Loeff, M., Dellwig, O., Shaw, T. J., et al. (2011). Radium-based pore water fluxes of silica, alkalinity, manganese, DOC, and uranium: A decade of studies in the German Wadden Sea. Geochimica et Cosmochimica Acta, 75(21), 6535-6555. https://doi.org/10.1016/j.gca.2011.08.037

Moore, W. S., \& Cai, P. (2013). Calibration of RaDeCC systems for ${ }^{223}$ Ra measurements. Marine Chemistry, 156, 130-137. https://doi.org/ 10.1016/j.marchem.2013.03.002

Moore, W. S., \& Krest, J. (2004). Distribution of ${ }^{223}$ Ra and ${ }^{224}$ Ra in the plumes of the Mississippi and Atchafalaya Rivers and the Gulf of Mexico. Marine Chemistry, 86(3-4), 105-119. https://doi.org/10.1016/j.marchem.2003.10.001 
Moore, W. S., \& Oliveira, J. (2008). Determination of residence time and mixing processes of the Ubatuba, Brazil, inner shelf waters using natural Ra isotopes. Estuarine, Coastal and Shelf Science, 76(3), 512-521. https://doi.org/10.1016/j.ecss.2007.07.042

Rodellas, V., Garcia-Orellana, J., Garcia-Solsona, E., Masqué, P., Domínguez, J. A., Ballesteros, B. J., et al. (2012). Quantifying groundwate discharge from different sources into a Mediterranean wetland by using ${ }^{222} \mathrm{Rn}$ and Ra isotopes. Journal of Hydrology, 466-467, 11-22. https://doi.org/10.1016/j.jhydrol.2012.07.005

Rodellas, V., Garcia-Orellana, J., Trezzi, G., Masqué, P., Stieglitz, T. C., Bokuniewicz, H., et al. (2017). Using the radium quartet to quantify submarine groundwater discharge and porewater exchange. Geochimica et Cosmochimica Acta, 196, 58-73. https://doi.org/10.1016/j gca.2016.09.016

Sanial, V., Kipp, L. E., Henderson, P. B., van Beek, P., Reyss, J. L., Hammond, D. E., et al. (2018). Radium-228 as a tracer of dissolved trace element inputs from the Peruvian continental margin. Marine Chemistry, 201, 20-34. https://doi.org/10.1016/j.marchem.2017.05.008

Scholten, J. C., Pham, M. K., Blinova, O., Charette, M. A., Dulaiova, H., \& Eriksson, M. (2010). Preparation of Mn-fiber standards for the efficiency calibration of the delayed coincidence counting system (RaDeCC). Marine Chemistry, 121(1-4), 206-214. https://doi.org/ 10.1016/j.marchem.2010.04.009

Sun, Y., \& Torgersen, T. (1998a). Rapid and precise measurement method for adsorbed ${ }^{224}$ Ra on sediments. Marine Chemistry, 61, 163-171. https://doi.org/10.1016/S0304-4203(98)00016-4

Sun, Y., \& Torgersen, T. (1998b). The effects of water content and Mn-fiber surface conditions on ${ }^{224}$ Ra measurement by $220 \mathrm{Rn}$ emanation. Marine Chemistry, 62(3-4), 299-306. https://doi.org/10.1016/S0304-4203(98)00019-X

Tamborski, J., van Beek, P., Rodellas, V., Monnin, C., Bergsma, E., Stieglitz, T., et al. (2019). Temporal variability of lagoon-sea water exchange and seawater circulation through a Mediterranean barrier beach. Limnology and Oceanography, 64(5), 2059-2080. https://doi. org/10.1002/lno.11169

Waska, H., Kim, S., Kim, G., Peterson, R. N., \& Burnett, W. C. (2008). An efficient and simple method for measuring ${ }^{226}$ Ra using the scintillation cell in a delayed coincidence counting system (RaDeCC). Journal of Environmental Radioactivity, 99(12), $1859-1862$. https://doi.org/10.1016/j.jenvrad.2008.08.008 